\title{
Dynamic Effect Analysis of the Coiled Tubing-in-riser System Considering the Operation and Environmental Parameters
}

\author{
Wenming Wang ${ }^{1,2, *}$, Yi Hao ${ }^{3,1}$, Zhenyu Wu ${ }^{1}$, Jinchao Fan ${ }^{1}$, Liyun $\mathrm{Lao}^{2}$, Yingchun $\mathrm{Chen}^{4}$ \\ (1. College of Mechanical and Transportation Engineering, China University of Petroleum-Beijing, Changping, \\ Beijing, 102249, China; 2. Centre for Thermal Energy Systems and Materials, Cranfield University, United \\ Kingdom; 3. China COMAC Shanghai Aircraft Design and Research Institute, Shanghai, 201210, China; 4. \\ College of Mechanical Engineering and Applied Electronics Technology, Beijing University of Technology, \\ Chaoyang District, Beijing, 100124, China.)
}

\begin{abstract}
The dynamic response of the coiled tubing (CT)-in-riser system is critical to the success of offshore CT operations. The purpose of this work is to investigate the mechanical behavior of the CT and the riser and analyze the influencing factors of the coupled system. This paper builds dynamic models of the micro elements of the CT and the riser, and then a coupled model of the CT-in-riser system is presented considering the excitation of ocean loads and the coupling interaction between the inner pipe and the outer pipe. The dynamic coupled model is solved by the finite element method. A finite element model of the CT-in-riser system is built using the Abaqus/AQUA module. The effect of the operating parameters including the top injection force, the top tension, the platform offset, the annular clearance, and the friction coefficient, and the environmental parameters including the ocean depth, current speed, wave period, and wave height are discussed. The results show that the top tension should be properly controlled; the platform offset and friction coefficients should be reduced; the annular clearance should be appropriately reduced; a low current speed and wave height should be selected for operation; and the wave period and wave height have a little effect on the CT axial force. This research can provide important theoretical support for the offshore CT application.
\end{abstract}

Key words: The CT; Riser; Finite element method; Influencing factor; Operating parameters; Environmental parameters.

*Corresponding author. E-mail: wangwenming@cup.edu.cn (W. Wang) 


\section{Introduction}

With the development of the offshore oil and gas industry, a large number of underwater production systems and well facilities have been deployed in ocean. The workover technology is an important safeguard for the safety of the oil and gas production equipment. The coiled tubing (CT), a continuous tube, can be several kilometers long and is an effective workover tool. It has been paid more and more attention to its incomparable advantages, such as high efficiency, low pollution, and fast deployment properties. Therefore, the CT has been gradually applied in operations such as well flushing, drilling, milling, fishing, etc. (Freitas et al., 2005; Lasseigne et al., 2015; Arrieta et al., 2011) [1-3]. As examples, Byron Jackson (BJ) Company of Canada conducted pigging applications in the deep waters of Brazil (Pinto et al., 2010) [4], and Chevron Pipelines accomplished workover applications after the CT is inserted into the marine riser in the Gulf of Mexico (Mark and Kaiser, 2016) [5]. Moreover, Aker Solutions of Norway proposed a plugging and abandonment operation using the CT and substituted the drillship equipped with drilling equipment for a CT operation vessel in 2014, which reduced operation cost and optimized its process (Aker Solutions Company, 2016) [6]. As a result, the CT is a promising application technology in the offshore workover domain.

However, the CT has an obvious disadvantage that its low bending stiffness leads to sinusoidal buckling or even helical buckling in the riser (Wang W.M. et al., 2012) [7]. The CT will deform from its original straight configuration into a curved shape as it buckles, and then the bending stress on the riser and the contact force between the $\mathrm{CT}$ and the riser will increase. It is noted that the interaction between the CT and the riser is more complicated under open sea conditions. Moreover, with the increase of water depth, the disturbance of wind, wave, and current are very likely to cause the coupled vibration of pipe strings. Therefore, the buckling and the coupled vibration may further lead to serious down-hole issues such as tubular string failure, hard slack off, and even "lock up" or the riser's breakage (Gao D.L. et al., 2014) [8].

There are a lot of studies on dynamics response of the riser, which are not only the influence of ocean currents and waves, but also the impact resulting from the movements of the vessel (Hong. et al., 2018) [9]. However, the CT-in-riser system is different with the single riser as the injected inner pipe. The buckling CT will change the stiffness, contact force, and stress distribution of the system. 
There are massive effects causing by the inner pipe. It is noted that there is a pipe-in-pipe structure in ocean engineering which consists of two pipes and is separated by insulation (Mark and Kaiser, 2016; Alrsai M. et al., 2018) [5, 10]. It maintains the temperature of the fluids to prevent formation of hydrates. However, its structure is different with the CT-in-riser system.

For CT-in-riser system problems, scholars have performed a number of theoretical and experimental studies on its mechanical behavior. Some research focuses on the axial load transfer and the buckling phenomenon of the CT under the coupling interaction between the inner pipe and the outer pipe. Falser (Falser et al., 2010) [11] analyzed the contact interaction between inner and outer pipes, and proposed the concept of pipe-in-pipe system. Guan (Guan F. et al., 2014; Guan F. et al., 2019) $[12,13]$ built a testing platform of CT in pipeline and discussed the buckling phenomenon of the CT by using the theory and experimental results. Chen (Chen et al., 2016; 2017; 2018) [14-16] analyzed the transfer efficiency of the inner pipe axial load under different boundary conditions by experimental study, and proposed methods that reduce the friction between the CT and the riser. Wang (Wang W. M. et al., 2018) [17] built a mathematical model and experiment of the CT-in-SCR system, and then the axial load transfer characteristic of the CT and the effects of inclined angle were discussed. Besides, it is noted that the structure of the CT-in-riser system is similar with that of offshore drill pipe system. Therefore, some researchers discussed the mechanical behavior of the outer pipe. The force, deformation and vibration of the drilling riser were investigated, and the factors including the movement of offshore platform, the marine environment loads, etc. were discussed. Morooka (Morooka et al., 1997) [18] presented a calculation method for contact forces in modeling the drill column using finite elements. Wang (Wang P. et al., 2014) [19] et al. established a static model of deep water riser under the influence of the drill string, which includes the coupling between riser and drill string. Wang (Wang Y. B. et al., 2015) [20] presented a coupled dynamic model to analyze the mechanical behavior of deep-water drilling columns under combined forcing and parametric excitation. Mao (Mao et al., 2016) [21] designed a test to analyze the dynamic response of a riser system in deep water. Liao (Liao et al., 2018) [22] established a dynamic model of offshore drilling system using the finite element simulation, and modelled the interaction between the inner and the outer pipe columns through $N$ elastic-friction units introduced along the pipe string. 
However, there are limited and systematical studies on the coupled dynamic analysis of the CT-in-riser system considering the environmental loads and the contact interaction. The riser is prone to have a bending deformation under the ocean loads. With the increase of the CT injection force, the contact interaction between the inner and the outer tubes will be more complex. Therefore, in order to ensure more reliable workover operation, it is crucial to analyze the coupled dynamics characteristics of the offshore tubing system.

In this paper, a coupled dynamics model of the CT-in-riser systems is described using the micro-element method, and then a simulation model is established to solve the coupled model. The lateral deformation, the bending moment and stress distribution of the riser and the output force of the $\mathrm{CT}$ are investigated under the influence of the operation and environment parameters.

\section{Mechanical models}

\section{1 system description}

A riser connects a floating vessel to wellhead, as shown in Fig. 1(a). According to the operational situation, there are two types of riser: the drilling riser and the production riser. The drilling riser is a vertical pipe used during drilling, and the production riser provides a conduit for the flow of crude oil and natural gas from the well to the production platform. The CT-in-riser system normally consists of a production riser and a CT, as shown in Fig. 1(b). The riser connects the offshore platform and the subsea wellhead by the upper and lower flexible joints respectively. In order to accomplish the workover operation, the CT firstly needs to enter the production riser through an injection head installed on the offshore platform.

A mechanical model of the CT-in-riser systems is extracted from the actual operation as shown in Fig. 1(c), and a coordinate system is built as follows: the origin $O$ is at the top of the riser; the $x$-axis is the horizontal direction; the z-axis is the vertical down direction. In order to simplify the mechanical models, the following assumptions are made:

(1) The cross sections of riser and the CT are round without considering the cross section changes;

(2) The riser and the CT are in linear elastic deformation;

(3) The top and bottom of the riser are hinged, regardless of rotational stiffness; 
(4) The riser is in uniform contact with the CT, and the friction coefficient of each contact position is unchanged;

(5) The transverse displacement of riser is small and controlled within 5\% of the ocean depth;

(6) The stiffness of the CT is negligible compared with riser stiffness.

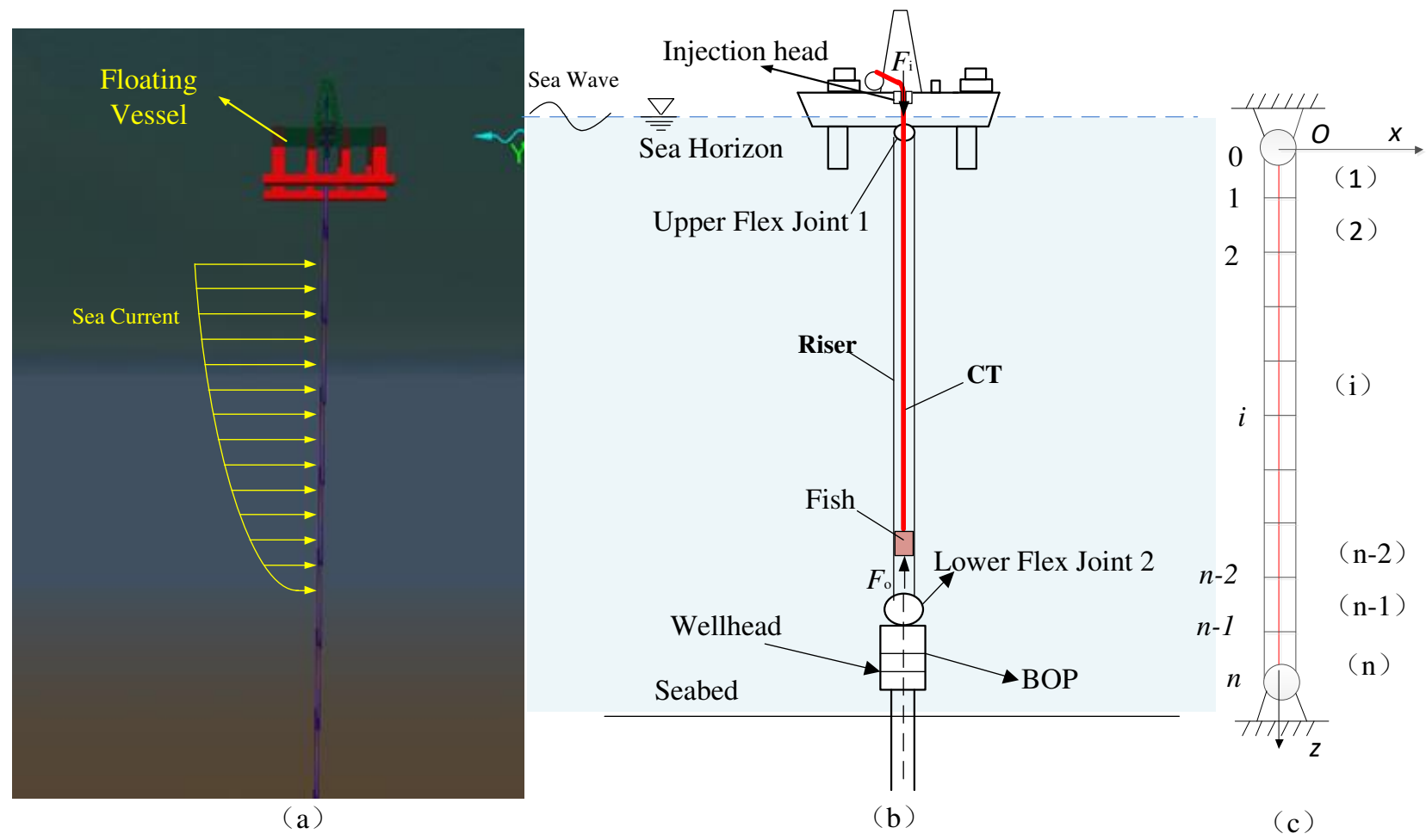

Fig. 1 Model of the CT-in-riser systems

\subsection{Micro element of the riser and CT}

The riser and the CT are divided into $n$ equal segments as shown in Fig.1 (c), and the length of the micro sections are $d$ s and $d$ s' respectively (Wang W.M. et al., 2018) [17]. The forces of the micro element of the riser and the CT are shown in Fig. 2. 


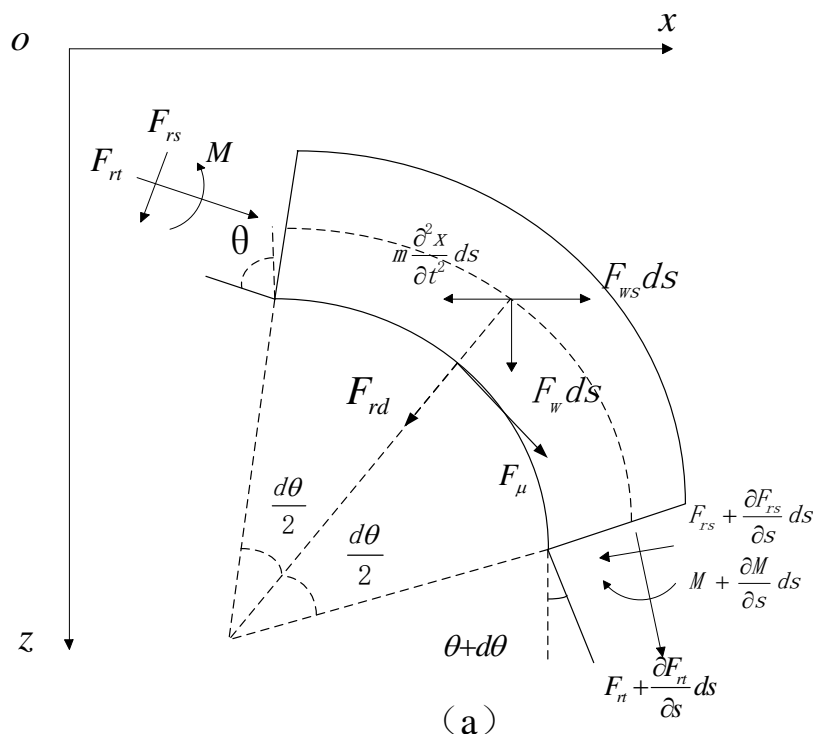

(a)

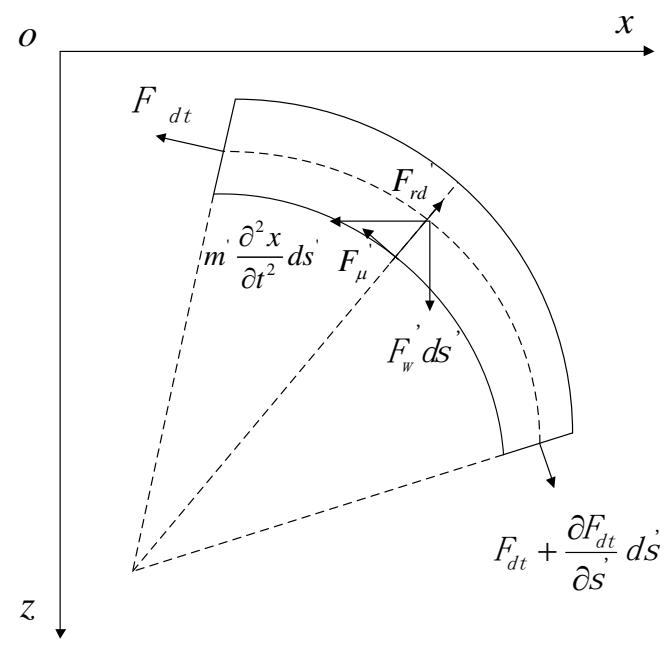

(b)

Fig.2 Mechanical models of the micro elements: (a) the riser; (b) the CT.

The micro element of the riser bears the gravity $F_{\mathrm{w}} \mathrm{ds}$, the inertia force $m \frac{\partial^{2} x}{\partial t^{2}} d s$, and the external load $F_{\text {ws }} \mathrm{d} s . F_{\text {rt }}$ is the tension of $d s, F_{\text {rs }}$ is the shear force of $d s$, and $M$ is the bending moment of $d s . \quad F_{\mu}$ is the friction along tangent direction between the CT and riser, and $F_{\text {rd }}$ is the normal stress between the CT and riser, $D_{r, \text { in }}$ is the inner diameter of the riser. According to the D'Alembert principle, the balance equations of the $x$-direction and $z$-direction and the torque balance equations of the riser are established as shown in Equation (1) (Wang W.M. et al., 2018) [17].

$$
\left\{\begin{array}{l}
-\frac{\partial F_{r s}}{\partial z}+\frac{\partial}{\partial z}\left(F_{r t} \frac{\partial x}{\partial z}\right)+F_{w s}-m \frac{\partial^{2} x}{\partial t^{2}}+F_{\mu} \frac{\partial x}{\partial z}-F_{r d}=0 \\
\frac{\partial F_{r t}}{\partial z}+\frac{\partial}{\partial z}\left(F_{r s} \frac{\partial x}{\partial z}\right)+F_{w}+F_{\mu}+F_{r d} \frac{\partial x}{\partial z}=0 \\
-E I \frac{\partial^{3} x}{\partial z^{3}}-F_{r s}+\frac{F_{\mu} D_{r, i n}}{2}=0
\end{array}\right.
$$

Where $E$ is the modulus of elasticity, $I$ is the moment of inertia of the section, and $m$ is the mass of the riser per unit length.

The force of the micro element of the CT is shown in Fig. 2(b). $F_{\mathrm{dt}}$ is the axial force, $F_{\mu}{ }_{\mu}$ is the friction; $m^{\prime}$ is the mass of the CT per unit length; $F_{w}^{\prime}$ is the submerged weight of the CT per unit length. Similarly, according to the D'Alembert principle, the micro-element of the CT is subjected to $x$-direction and $z$-direction equilibrium analysis, and then the Equation (2) is obtained. 


$$
\left\{\begin{array}{l}
\frac{\partial}{\partial z}\left(F_{d t} \frac{\partial x}{\partial z}\right)-m^{\prime} \frac{\partial^{2} x}{\partial t^{2}}-F_{\mu} \cdot \frac{\partial x}{\partial z}+F_{r d}{ }^{\prime}-A F_{r d} \cdot \frac{\partial^{2} x}{\partial z^{2}}=0 \\
\frac{\partial F_{d t}}{\partial z}+F_{w}^{\prime}-A F_{w}^{\prime} \frac{\partial^{2} x}{\partial z^{2}}-F_{\mu}^{\prime}+A F_{\mu} \frac{\partial^{2} x}{\partial z^{2}}-F_{r d} \cdot \frac{\partial x}{\partial z}=0
\end{array}\right.
$$

Where, $D_{\mathrm{d}, 0}$ is the outer diameter of the pipe; $A=\frac{D_{\mathrm{r}, \mathrm{in}}}{2}-\frac{D_{\mathrm{d}, 0}}{2}$.

\subsection{Ocean loads}

In this study, the combined force of waves and currents $F_{w s}(z)$ in the water depth $z$ is calculated using the Morison equation (Mao et al., 2016) [21] as shown in Equation (3).

$$
F_{w s}(z)=\frac{1}{2} C_{D} \rho_{w} D|(v+u)|(v+u)+C_{M} \rho_{w} \frac{\pi D^{2}}{4} a_{x}
$$

Where, $D$ is the outer diameter of the riser; $v$ is the current velocity; $u$ is the wave velocity; $a_{x}$ is the wave acceleration along the direction of $x$-axis; $\rho_{w}$ is the seawater density. The drag coefficient $C_{D}=1.2$ and the inertia coefficient $C_{M}=2.0$ are assumed (Wang et al., 2015) [20]. The current velocity $v$ changes with the water depth $z$, as follows:

$$
v=v_{m}\left(\frac{H-z}{H}\right)+v_{r}\left(\frac{H-z}{H}\right)^{\frac{1}{7}}
$$

Where, $v_{m}$ is the wind speed; $v_{r}$ is the tide speed at surface of sea; and $H$ is the total water depth.

The wave force is solved by the theory of two-dimensional waves (Mao et al., 2016) [21]. The velocity and acceleration components in the direction of $x$-axis can be obtained by the potential function. The wave velocity $u$ and wave acceleration $a_{x}$ are shown in Equation (5).

$$
\left\{\begin{array}{l}
u=\frac{\pi H}{T} \frac{\cosh [k(z+h)]}{\sinh (k h)} \cos (k x-\varpi t) \\
a_{x}=\frac{2 \pi^{2} H}{T^{2}} \frac{\cosh [k(z+h)]}{\sinh (k h)} \sin (k x-\varpi t)
\end{array}\right.
$$

Where, $k$ is wave number, $T$ is wave period, $\varpi$ is wave frequency, and $h$ is wave height. 


\subsection{Solution of the coupled model}

The Equation (1) and Equation (2) are combined and the friction equation is added, and then the coupled model of the CT-in-riser can be obtained as shown in equation (6).

$$
\left\{\begin{array}{l}
-\frac{\partial F_{r s}}{\partial z}+\frac{\partial}{\partial z}\left(F_{r t} \frac{\partial x}{\partial z}\right)+F_{w s}-m \frac{\partial^{2} x}{\partial t^{2}}+F_{\mu} \frac{\partial x}{\partial z}-F_{r d}=0 \\
\frac{\partial}{\partial z}\left(F_{r s} \frac{\partial x}{\partial z}\right)+\frac{\partial F_{r t}}{\partial z}+F_{w}+F_{\mu}+F_{r d} \frac{\partial x}{\partial z}=0 \\
-E I \frac{\partial^{3} x}{\partial z^{3}}-F_{r s}+\frac{F_{\mu} D_{r, i n}}{2}=0 \\
\frac{\partial}{\partial z}\left(F_{d t} \frac{\partial x}{\partial z}\right)-m^{\prime} \frac{\partial^{2} x}{\partial t^{2}}-F_{\mu} \cdot \frac{\partial x}{\partial z}+F_{r d} \cdot A F_{r d} \cdot \frac{\partial^{2} x}{\partial z^{2}}=0 \\
\frac{\partial F_{d t}}{\partial z}+F_{w}{ }^{\prime}-A F_{w}^{\prime} \frac{\partial^{2} x}{\partial z^{2}}-F_{\mu}^{\prime}+A F_{\mu} \cdot \frac{\partial^{2} x}{\partial z^{2}}-F_{r d} \frac{\partial x}{\partial z}=0 \\
F_{\mu}=\mu \cdot F_{\mathrm{rd}}
\end{array}\right.
$$

There are 6 unknown parameters: $F_{\mathrm{rs}}, F_{\mathrm{rt}}, F_{\mathrm{dt}}, F_{\mu}, F_{\mathrm{rd}}$, and $x$. Thus, equations can be solved because the quantity of equations and unknown parameters is equal.

According to the actual situation, the boundary conditions of the CT are as follows: the axial force imposed by the injector head at the top CT can be measured and is a constant; the bottoms of the $\mathrm{CT}$ and the riser have no displacement along $x$ direction, and the displacement of the top is a constant value. Boundary condition of CT-in-riser systems is shown in Equation (7).

$$
\left\{\begin{array}{l}
\left.x\right|_{z=0}=\text { const } 1,\left.\quad F_{\mathrm{d} t}\right|_{z=0}=\text { const } 2,\left.\quad E I \frac{\partial^{2} x}{\partial z^{2}}\right|_{z=0}=0 \\
\left.x\right|_{z=H}=0,\left.\quad E I \frac{\partial^{2} x}{\partial z^{2}}\right|_{z=H}=0
\end{array}\right.
$$

Assuming $F_{\mathrm{rt}}$ and $F_{\mathrm{dt}}$ are independent of time $t$, the coupled vibration equation of the CT-in-riser system is obtained when equation (6) is simplified.

$$
E I \frac{\partial^{4} x}{\partial z^{4}}-\left(F_{w}+F_{w}^{\prime}\right) \frac{\partial x}{\partial z}+\left[\left(F_{r t}+F_{d t}\right)_{0}-\left(F_{w}+F_{w}^{\prime}\right) \cdot z\right] \frac{\partial^{2} x}{\partial z^{2}}+F_{w s}+\left(m+m^{\prime}\right) \frac{\partial^{2} x}{\partial t^{2}}+\phi=0
$$

Where $\phi$ is coupled term.

$$
\begin{aligned}
& \phi=-\frac{D_{r, i n}}{2} \frac{\partial F_{\mu}}{\partial z}+A F_{r d} \frac{\partial^{2} x}{\partial z^{2}}+\left(A F_{w} \cdot \frac{\partial^{2} x}{\partial z^{2}}+A F_{\mu} \frac{\partial^{2} x}{\partial z^{2}}-\frac{\partial}{\partial z}\left(F_{r s} \frac{\partial x}{\partial z}\right)\right) \frac{\partial x}{\partial z} \\
& -\left[\int_{0}^{z}\left(A F_{w} \frac{\partial^{2} x}{\partial z^{2}}+A F_{\mu} \frac{\partial^{2} x}{\partial z^{2}}-\frac{\partial}{\partial z}\left(F_{r s} \frac{\partial x}{\partial z}\right)\right) d z\right] \frac{\partial^{2} x}{\partial z^{2}}
\end{aligned}
$$

The expression of $\phi$ shows that the coupled term includes $F_{\text {rd }}, F_{\mu}, A$ and so on. It means that the coupled relationship of the system is caused by the contact force and the annulus clearance. 
However, the contact between the inner pipe and the outer pipe is random. The solution of the contact problem needs to solve the friction response, and the calculation results are difficult to converge (Liao et al., 2018) [22]. Moreover, the coupled model shown in equation (8) is a fourth-order partial differential equation. It is not only necessary to replace the differential using the implicit center difference formula in space and time, but also the coupled interaction between the columns needs to be considered. When the proposed coupled model is substituted by the difference equation, the repeated iterations will dramatically increase. Therefore, it is difficult to solve this problem using analytical method. In order to analyze the coupled model, the finite element method and Abaqus software are used to solve the problem.

\section{Numerical model}

The three-dimensional finite element model of the CT-in-riser system is shown in Fig. 3(a) (Wang et al., 2018) [17]. The water depth is $1000 \mathrm{~m}$, the outside diameter of the riser is $533 \mathrm{~mm}$, and the diameter of the $\mathrm{CT}$ is $88.9 \mathrm{~mm}$. The material parameters are shown in Table 1. Because the riser uses upper and lower flexible joints to connect with other equipment, the connector element, CONN3D2 which includes a joint-rotation combination, is used to describe them. The CT is beam element B31 which is length of $0.5 \mathrm{~m}$, and is divided into 2000 elements. The riser is also B31 element. Considering the element quality, the riser is divided into 16448 elements. In this work, the internal tube-to-tube (ITT) contact element (Faes K et al., 2019) [23] provided by Abaqus are selected to simulate the three-dimensional pipe-in-pipe contact problems, which assumes that the relative slip is along the axial direction of pipe and the slip line is defined on the riser.

Table1 Parameters of the model.

\begin{tabular}{ll|ll}
\hline Parameter & Value & Parameter & Value \\
\hline Depth of water & $1000 \mathrm{~m}$ & Injection force & $10^{5} \mathrm{~N}$ \\
water density & $1030 \mathrm{~kg} / \mathrm{m}^{3}$ & Modulus of elasticity & $206 \mathrm{GPa}$ \\
Overall riser length & $1000 \mathrm{~m}$ & Top tension coefficient & 1.2 \\
Outer diameter of riser & $533 \mathrm{~mm}$ & Poisson's ratio & 0.3 \\
Riser wall thickness & $25.4 \mathrm{~mm}$ & Drilling fluid density & $800 \mathrm{~kg} / \mathrm{m}^{3}$ \\
Riser density & $7850 \mathrm{~kg} / \mathrm{m}^{3}$ & Wave height & $4.0 \mathrm{~m}$ \\
CT outer diameter & $88.9 \mathrm{~mm}$ & Wave period & $8 \mathrm{~s}$ \\
CT wall thickness & $4.8 \mathrm{~mm}$ & Surface current velocity & $1.0 \mathrm{~m} / \mathrm{s}$ \\
\hline
\end{tabular}




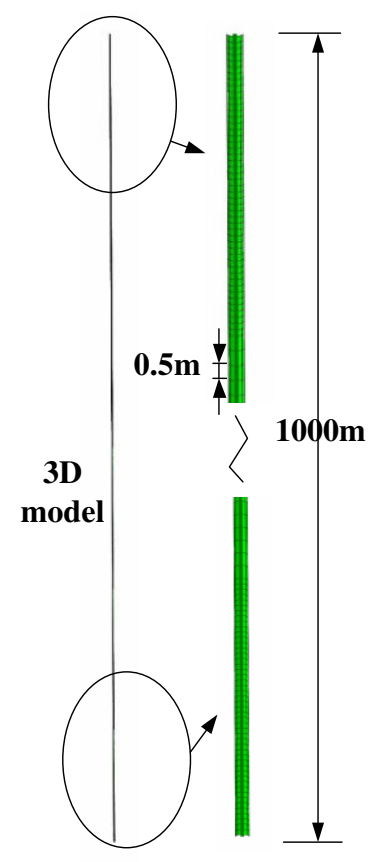

(a)

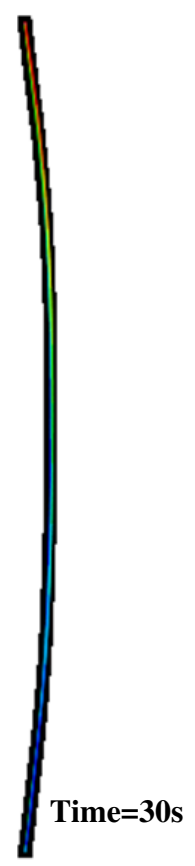

(b)

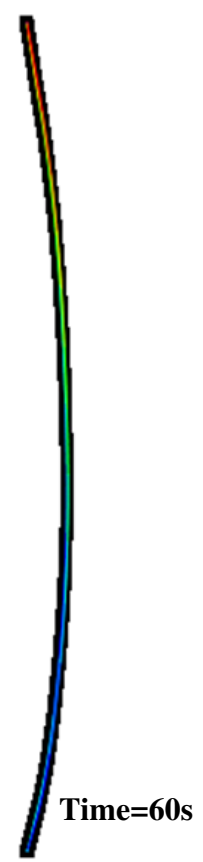

(c)

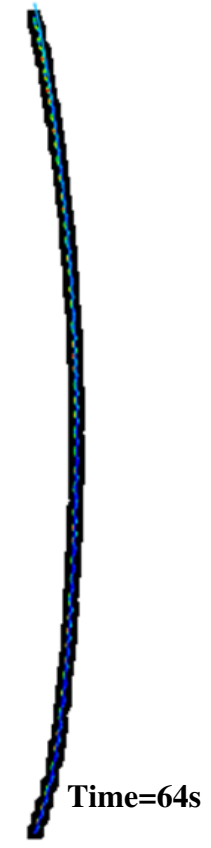

(d)

Fig. 3 Simulation results. (a) the finite element model; (b) the dynamic response process I; (c) the dynamic response process II; (d) the dynamic response process III.

\subsection{Dynamic response process}

The sea state of level 5 is chosen and the parameters are shown in Table 1 . The wave height is $4.0 \mathrm{~m}$, the surface current velocity is taken as $1 \mathrm{~m} / \mathrm{s}$ and the wave period is $8 \mathrm{~s}$. The environmental parameters are loaded by Abaqus/AQUA module using the INP code. It is defined that the current speed of the seabed and sea surface is $0 \mathrm{~m} / \mathrm{s}$ and $1 \mathrm{~m} / \mathrm{s}$ in the AQUA module.

The dynamic response process of the calculation results are shown in Fig. 3(b)-(d), which is the simulation results at $30 \mathrm{~s}, 60 \mathrm{~s}$, and $64 \mathrm{~s}$. It is shown that the stress and lateral displacement distribution of the CT-in-riser system changes during the operation process. Fig. 3(b) and Fig. 3(c) have no injection force at the top of the CT, only ocean loads. The injection force is applied till $60 \mathrm{~s}$, and the simulation result is shown in Fig. 3(d).

\subsection{Grid independence analysis}

To verify the grid independence, the length of CT element is divided into $2 \mathrm{~m}, 1 \mathrm{~m}, 0.5 \mathrm{~m}$, and $0.2 \mathrm{~m}$, and the quantity of riser elements changes in multiples. After the simulation is achieved, the simulation results are shown in Table 2. 
Table 2 Simulation results under different grid.

\begin{tabular}{ccccc}
\hline \multirow{2}{*}{ Item } & \multicolumn{4}{c}{ The length of the CT element } \\
\cline { 2 - 5 } & $2 \mathrm{~m}$ & $1 \mathrm{~m}$ & $0.5 \mathrm{~m}$ & $0.2 \mathrm{~m}$ \\
\hline Output force of the CT $(\mathrm{N})$ & No convergence & $2.372 \times 10^{5}$ & $2.457 \times 10^{5}$ & $2.441 \times 10^{5}$ \\
$\begin{array}{c}\text { Displacement of the riser }(\mathrm{m}) \\
\text { Bending moment of the riser } \\
\quad \text { (after loading, } \mathrm{N} \cdot \mathrm{m})\end{array}$ & No convergence & 9.171 & 9.510 & 9.733 \\
Stress of the riser $(\mathrm{Pa})$ & No convergence & -55349.1 & -57673.8 & -59865.4 \\
\hline
\end{tabular}

Table 2 indicates that the number of grids has a great influence on the simulation results. When the length of the CT element is $2 \mathrm{~m}$, the calculation is not converged. When the length of the CT element is less than $1 \mathrm{~m}$, the simulation results change little. Therefore, the element of $0.5 \mathrm{~m}$ is applied in this simulation study.

\section{Simulation results}

As the dynamic response of the CT-in-riser system is complicated, several factors need to be considered, for example: the ocean loads are complex and variable; the length of the riser can reach kilometers; and there is coupled interaction between the inner and outer pipelines. The dynamic response is mainly affected by the operating parameters and the environmental parameters (Wang et al., 2015) [20]. The operating parameters include the top injection force, the top tension, the platform offset, the annular clearance, and the friction coefficient. The environmental parameters include the water depth, the current speed, the wave period, and the wave height. Through changing the operation condition of the finite element model, the effects of those two type parameters are discussed.

\subsection{Effect of the operation parameters}

\section{(1) Injection force of CT}

In order to investigate the trend of the output force $F_{\mathrm{o}}$ at the bottom of the CT with the injection force $F_{\mathrm{i}}$ at the top of the $\mathrm{CT}$ as shown in Fig. 1 (b), the injection force increase from $0 \mathrm{~N}$ to $100 \mathrm{KN}$, and three top injection forces of $80 \mathrm{KN}, 90 \mathrm{KN}$ and $100 \mathrm{KN}$ are selected. The calculation parameters are shown in table 1(Guan F. et al., 2014) [12]. The results including the output force of the CT, the lateral displacement, stress and bending moment of the riser are shown in Fig. 4. 

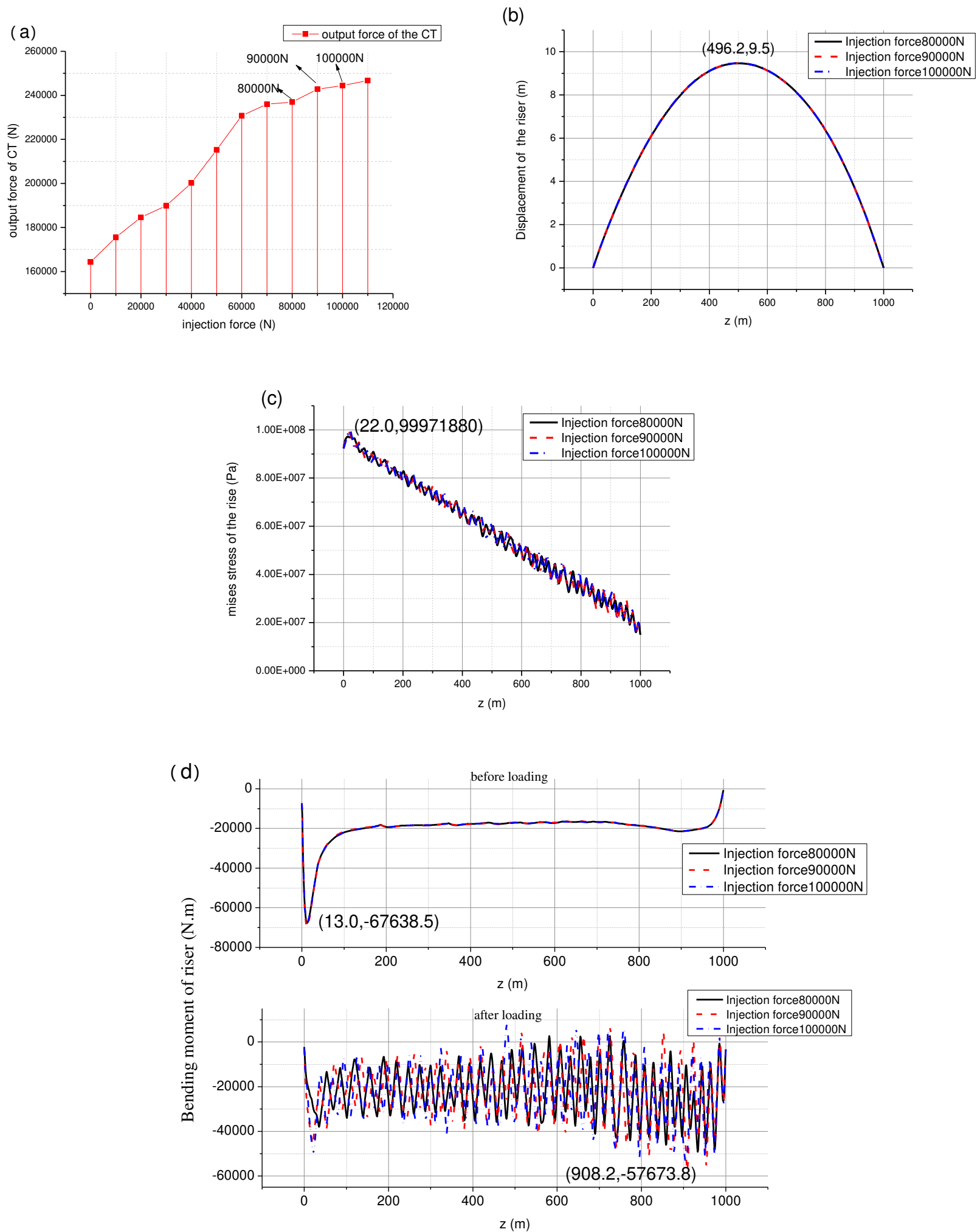

Fig. 4 Effect of the injection force of the CT: (a) output force of the CT; (b) displacement of the riser; (c) Mises stress of the riser; (d) bending moment of the riser. 
Fig. 4(a) shows that with the increase of the injection force, the output force of the CT rise up gradually. The output force is $164.29 \mathrm{kN}$ when the injection force is $0 \mathrm{~N}$, which is caused by the self-weight of the CT.

The maximum lateral displacement along the riser is $9.5 \mathrm{~m}$ as shown in Fig. 4(b). Fig. 4(c) indicates that the maximum stress of the riser is $99.97 \mathrm{MPa}$ at the initial section. Moreover, Fig. 4(d) shows that the maximum bending moment is $67.6 \mathrm{KN} \cdot \mathrm{m}$ when the injection force is not added, while the maximum bending moment is $57.7 \mathrm{KN} \cdot \mathrm{m}$ when the injection force is loaded. The bending moment of the riser has a serrated aspect along the riser length. It is causes by discrete contact points between the $\mathrm{CT}$ and the riser in the buckling pattern.

Fig. 4 indicates that the growth of the injection force reinforces the coupled contact force, which can affects the stress and bending moment distribution of the CT-in-riser system. However, the change of injection force has little effect on the lateral displacement, stress and bending moment of the riser. The reason is that the riser has a much larger bending stiffness than the CT, and then the CT is confined in the riser configuration.

\section{(2) Top tension of riser}

To analyze the effect of top tension, three top tension coefficients $(1.2,1.4$ and 1.6) are selected. Other parameters in table 1 are unchanged, and then the results are shown in Fig. 5.
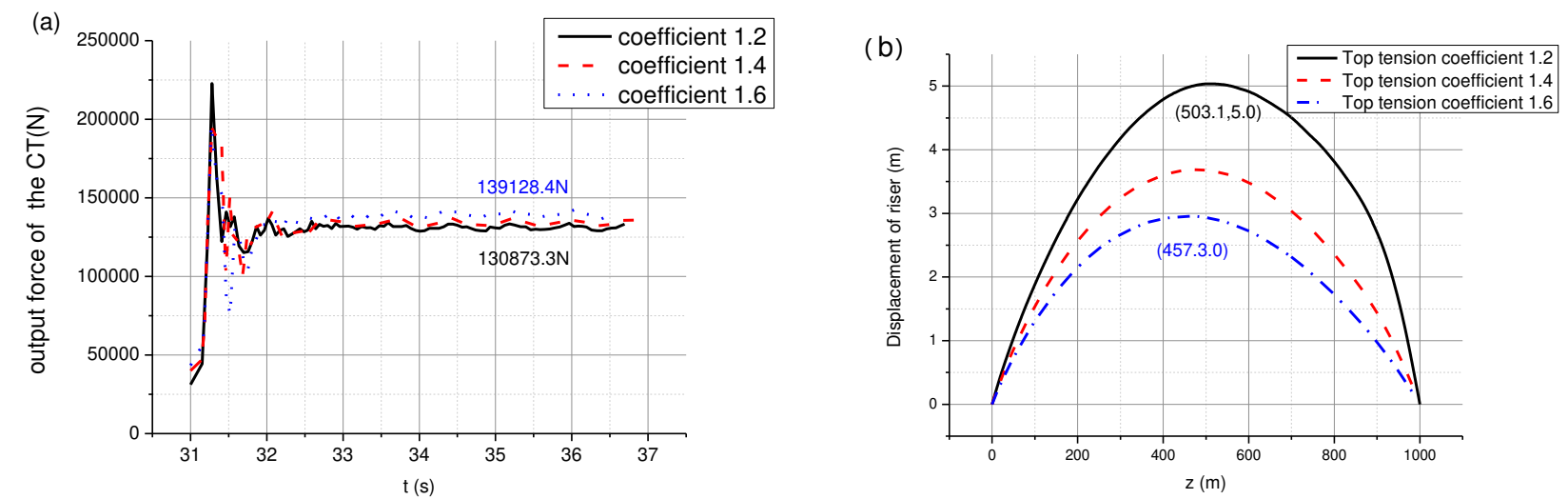

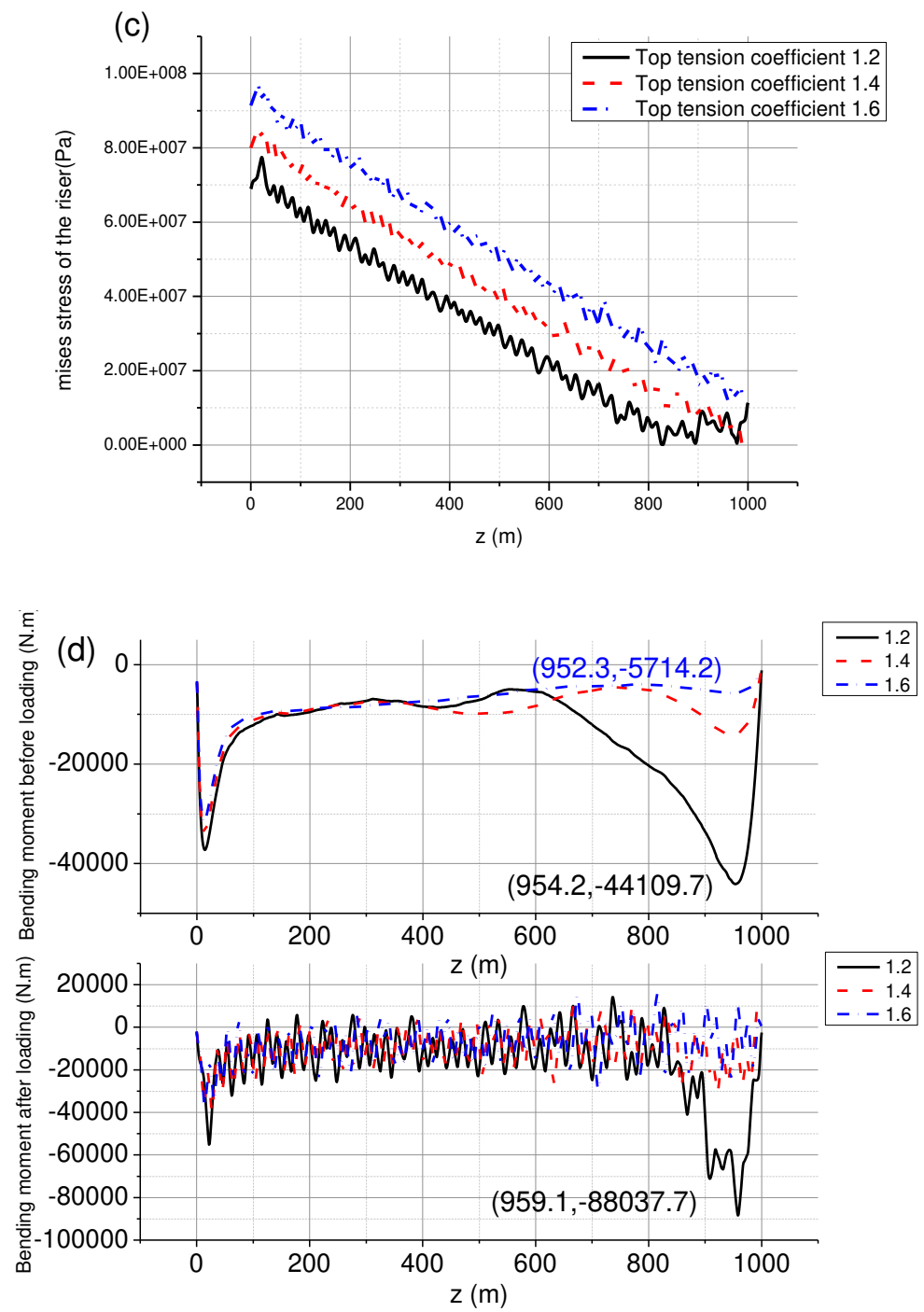

Fig. 5 Effect of top tension of the riser: (a) Output force of the CT; (b) Displacement of the riser; (c) Mises stress of the riser; (d) Bending moment of the riser.

Fig. 5(a) shows that the output force of the CT will rise up with the top tension coefficient when the system is in a stable situation. The maximum difference of the output force is $8255.1 \mathrm{~N}$ when the coefficient is 1.6 and 1.2. The reason is that the larger top tension increases the bending stiffness of the CT-in-riser system and reduces the lateral displacement of the system, and then improves the work efficiency of the CT's injection.

Fig. 5(b) indicates that increasing the top tension reduces the lateral displacement of the riser. The maximum difference of the lateral displacement is $2 \mathrm{~m}$ under the coefficients of 1.6 and 1.2. However, riser stress will grow along with the increase of the top tension as shown in figure 5 (c). 
In Fig. 5(d), the maximum bending moment of the riser will decrease along the increase of the top tension. The maximum bending moment at $50 \mathrm{~m}$ above the wellhead is $44.1 \mathrm{KN} \cdot \mathrm{m}$ before loading injection force. After the CT loads the injection force, the bending moment of the riser has a severe fluctuation and has an increase of $43.9 \mathrm{KN} \cdot \mathrm{m}$ when the coefficient is 1.2 , which is caused by the coupled interaction between the $\mathrm{CT}$ and the riser.

In summary, the increase of the top tension can improve the efficiency of the CT operation and reduce the lateral displacement and the bending moment of the riser. The top tension is one of the important factors that can be controlled during the operation.

\section{(3) Platform offset}

The platform often deviates from the optimal position because of the effect of the ocean loads. Four platform offsets of $0 \mathrm{~m}, 10 \mathrm{~m}, 30 \mathrm{~m}$ and $50 \mathrm{~m}$ are selected to investigate the CT-in-riser system. The calculation parameters are shown in table1 and the results are shown in Fig. 6.

(a)

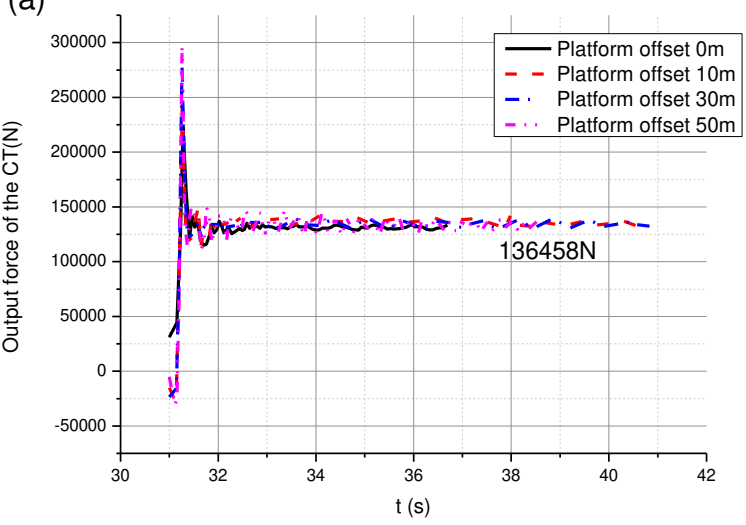

(b)

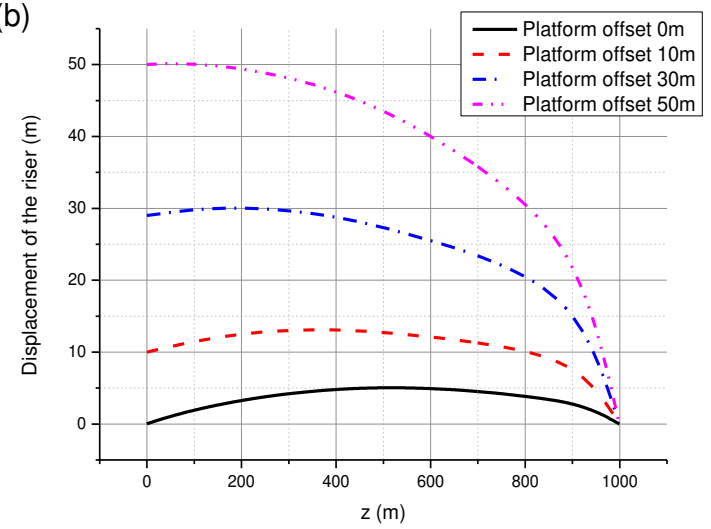

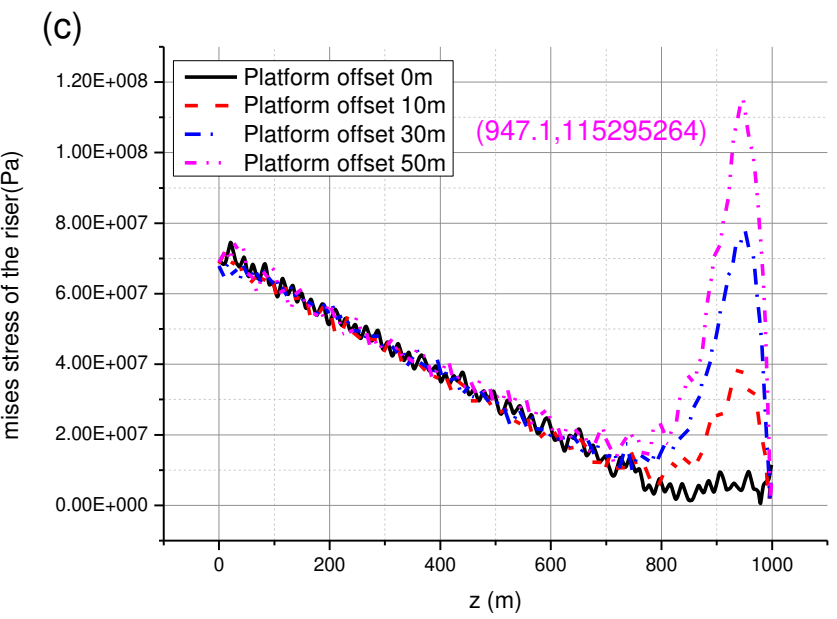




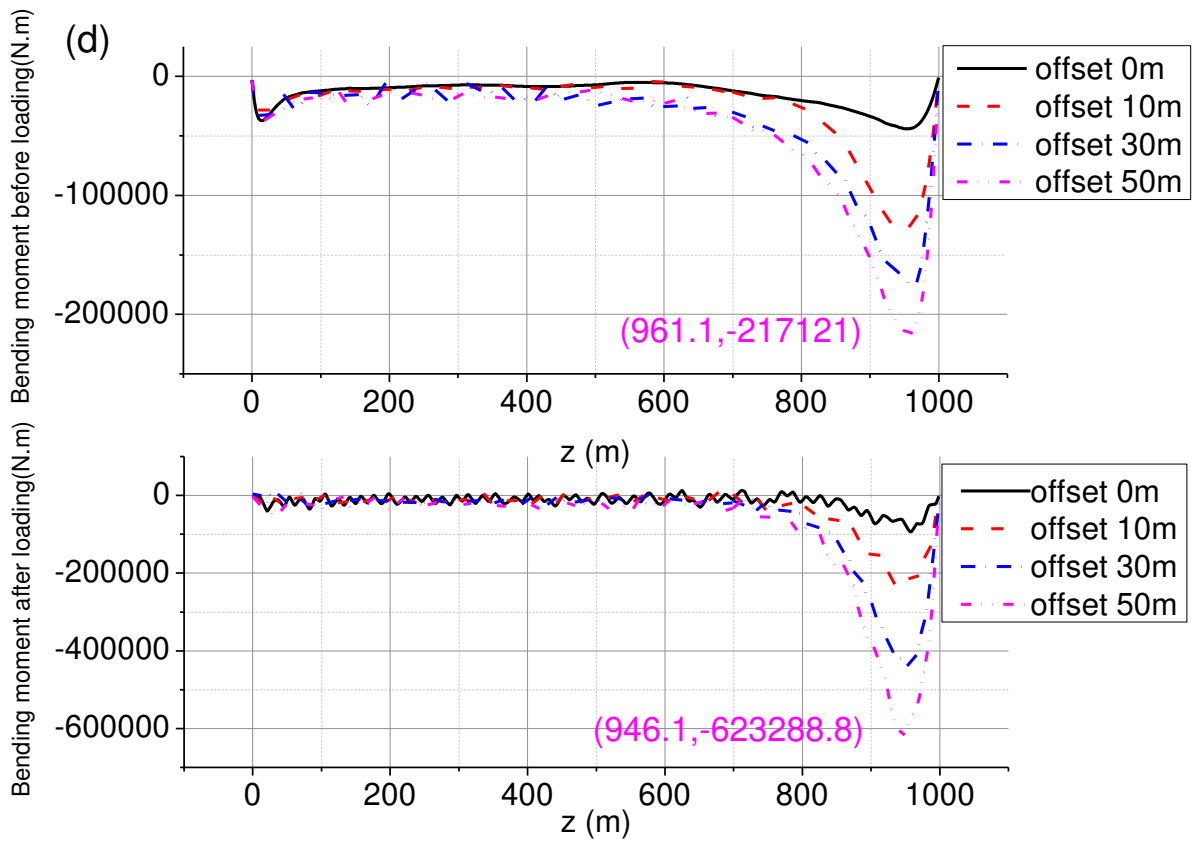

Fig. 6 Effect of platform offset: (a) output force of the CT; (b) displacement of the riser; (c) Mises stress of the riser; (d) bending moment of the riser.

Fig. 6(a) shows that the platform offset has little effect on the axial force transmission; Fig. 6(b) indicates that the shape of the CT-in-riser system is catenary and the displacement of the riser will rise up with the growth of the top offset, which causes by the existence of ocean load and gravity.

The Mises stress of the riser is in a linear state from $0 \mathrm{~m}$ to $800 \mathrm{~m}$ as shown in Fig. $6(\mathrm{c})$. The stress increases dramatically with the rise of the platform offset. The maximum stress is $115.3 \mathrm{MPa}$ when the platform offset is $50 \mathrm{~m}$.

The same phenomenon is reflected in the bending moment of the riser. Fig. 6(d) shows that the maximum bending moment of $50 \mathrm{~m}$ is $217.1 \mathrm{KN} \cdot \mathrm{m}$ without injection force. Moreover, the maximum bending moment is $623.3 \mathrm{KN} \cdot \mathrm{m}$ when the injection force is loading. It is illustrated that the riser rotation angle related to the vertical direction at the bottom has a significant influence, and causes a Von Mises peak near the bottom (Liao et al., 2018) [22].

The platform offset results in an change of the stress, bending moment and displacement of the riser. With the rise of the platform offset, the stress and bending moment increase significantly near the wellhead of $50 \mathrm{~m}$. In order to ensure safe operation, the riser should be vertical as much as possible to have a smaller peak causing by the riser rotation angle at the bottom. In actual operation, 
the investigated offsets of the riser are all in the downstream direction, thus the vessel usually has some upstream offset.

\section{(4) Annular clearance}

To explore the influence of annular clearance between the inner and outer pipe, three CT outer diameters of $88.9 \mathrm{~mm}, 114.3 \mathrm{~mm}$ and $141.3 \mathrm{~mm}$ are selected, and then the corresponding annular clearance are $196.7 \mathrm{~mm}, 139.5 \mathrm{~mm}$ and $126.0 \mathrm{~mm}$, respectively. Other parameters remain unchanged as shown in Table 1, and the calculation results are shown in Fig. 7.

(a)

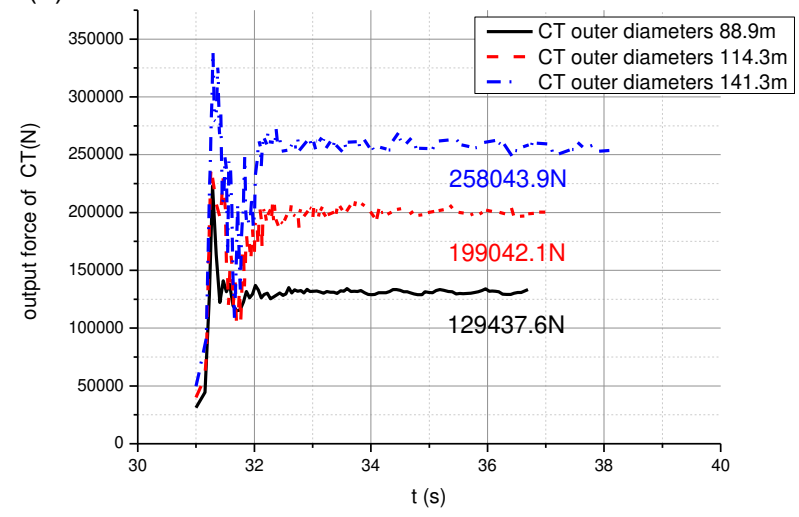

(b)

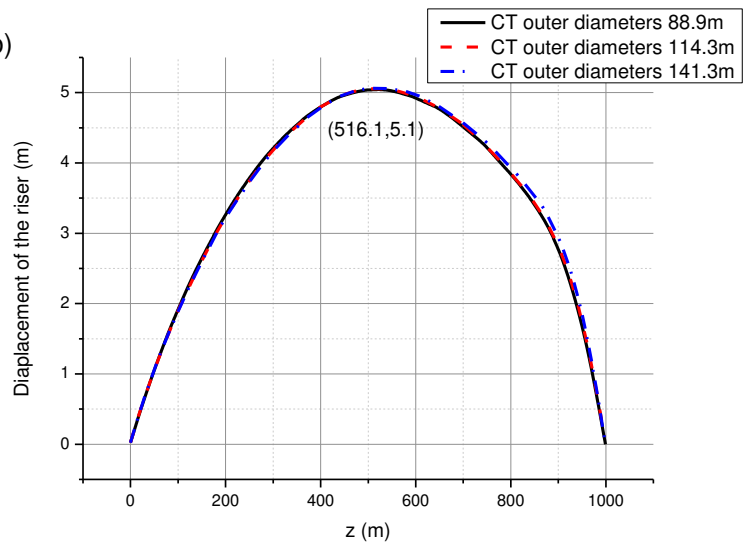

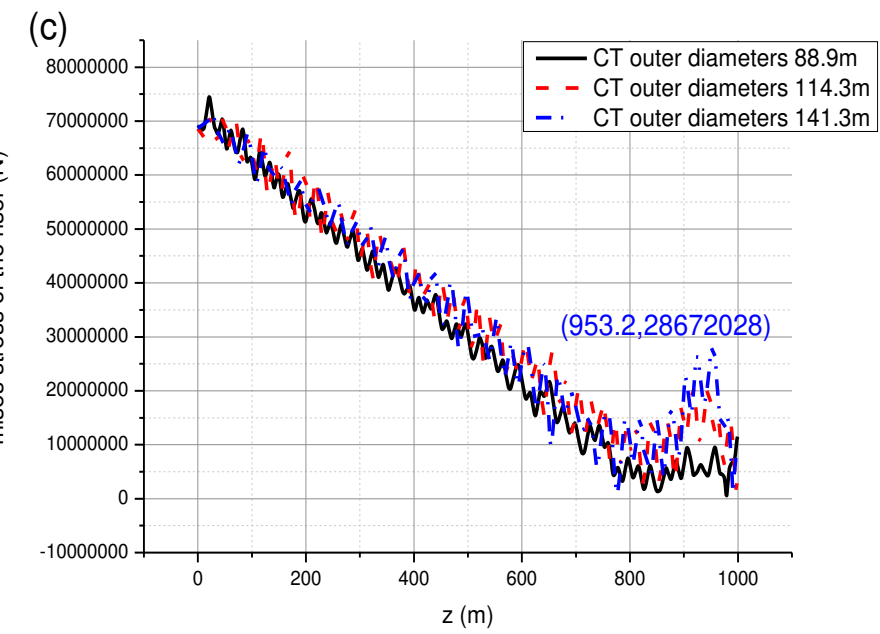




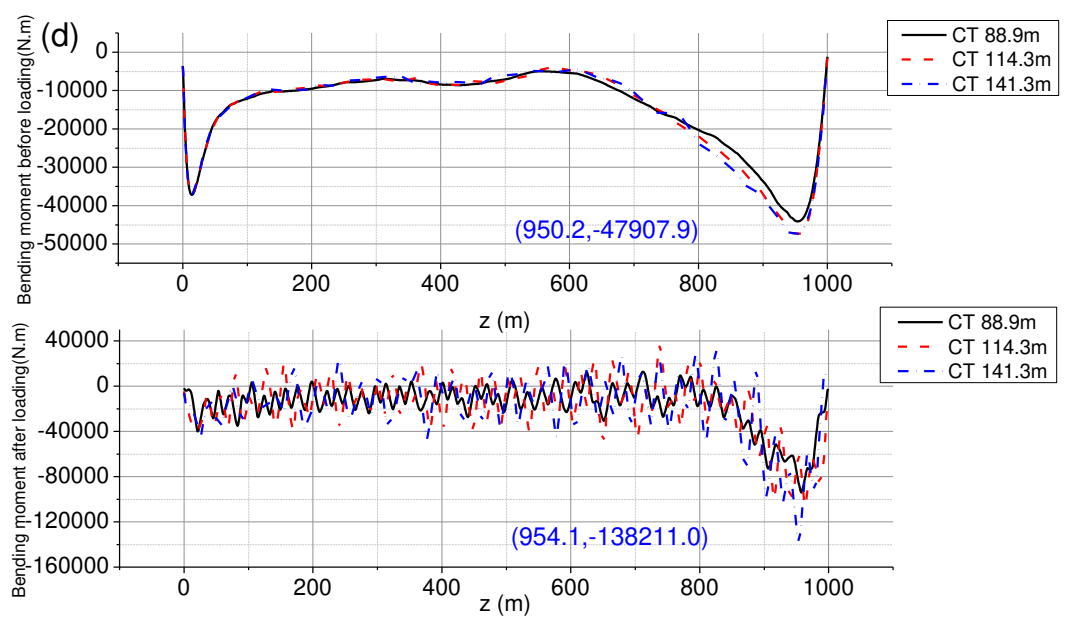

Fig. 7 Effect of annular clearance: (a) output force of the CT; (b) displacement of the riser; (c) Mises stress of the riser; (d) bending moment of the riser.

Fig. 7(a) shows that the smaller the annular clearance is, the higher the axial force transmission efficiency is. The reason is that the deformation of the smaller diameter of the CT is more likely to occur under the same load, which will increase the contact force with the riser. Thus, the axial force transmission efficiency would reduce with the increase of the frictional resistance.

Fig. 7(b) shows that the maximum displacement is $5.1 \mathrm{~m}$. The annular clearance has little effect on the lateral displacement of the riser. The stress of the riser decreases with the water depth as shown in Fig. 7(c). From the water depth of $800 \mathrm{~m}$ to $1000 \mathrm{~m}$, the smaller annular clearance is, and the bigger stress is. There is a maximum stress of $28.7 \mathrm{MPa}$. The reason is that with higher CT diameters, the CT buckling mode is lower due to its increased bending stiffness. With fewer contact points between it and the riser, higher contact force will occur in these points, and then there are the higher peaks in riser response.

In Fig. 7(d), the maximum bending moment occurs at near the subsea wellhead of $50 \mathrm{~m}$, and the bending moment near the subsea wellhead increases with the rise of the outer diameter of the CT. When the outer diameter is $141.3 \mathrm{~mm}$, the maximum bending moment is $138.2 \mathrm{KN} \cdot \mathrm{m}$.

The outer diameter of the $\mathrm{CT}$ increases is beneficial to the transmission of the axial force of the CT, but will increase the stress and bending moment near the subsea wellhead of $50 \mathrm{~m}$. 


\section{(5) Friction coefficient}

In order to study the influence of friction coefficient, four friction coefficients of $0,0.1,0.3$ and 0.5 are chosen. The calculation results are shown in Fig. 8 .
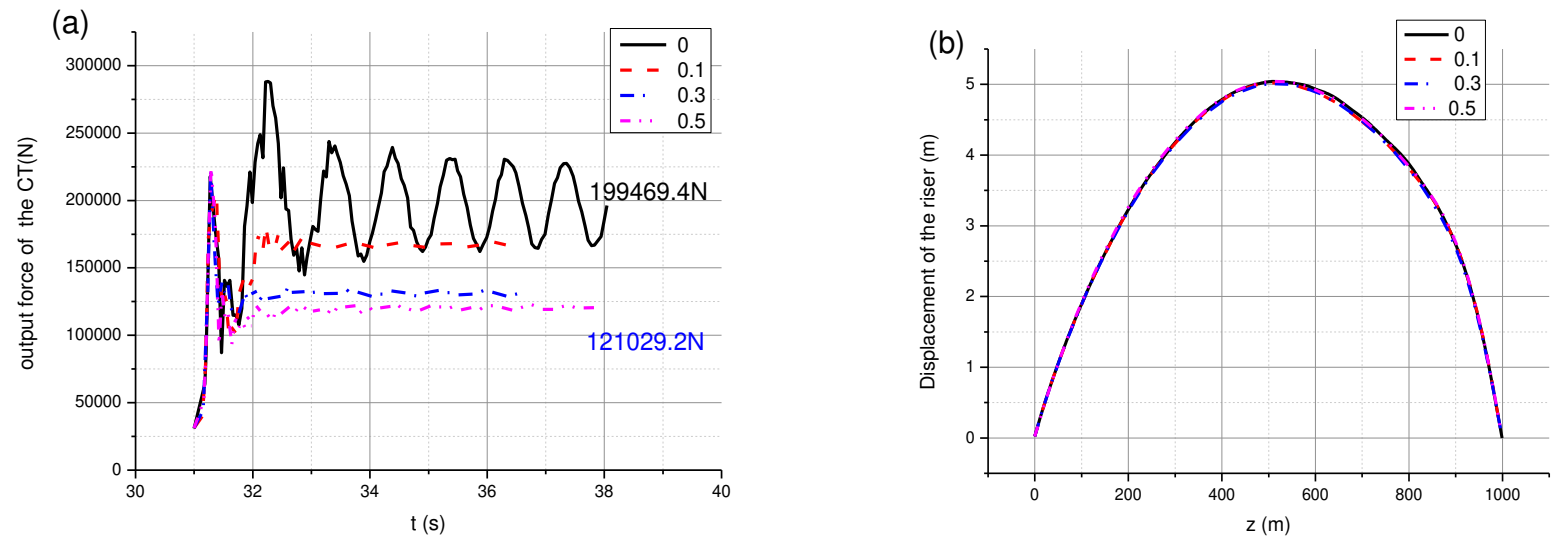

(c)
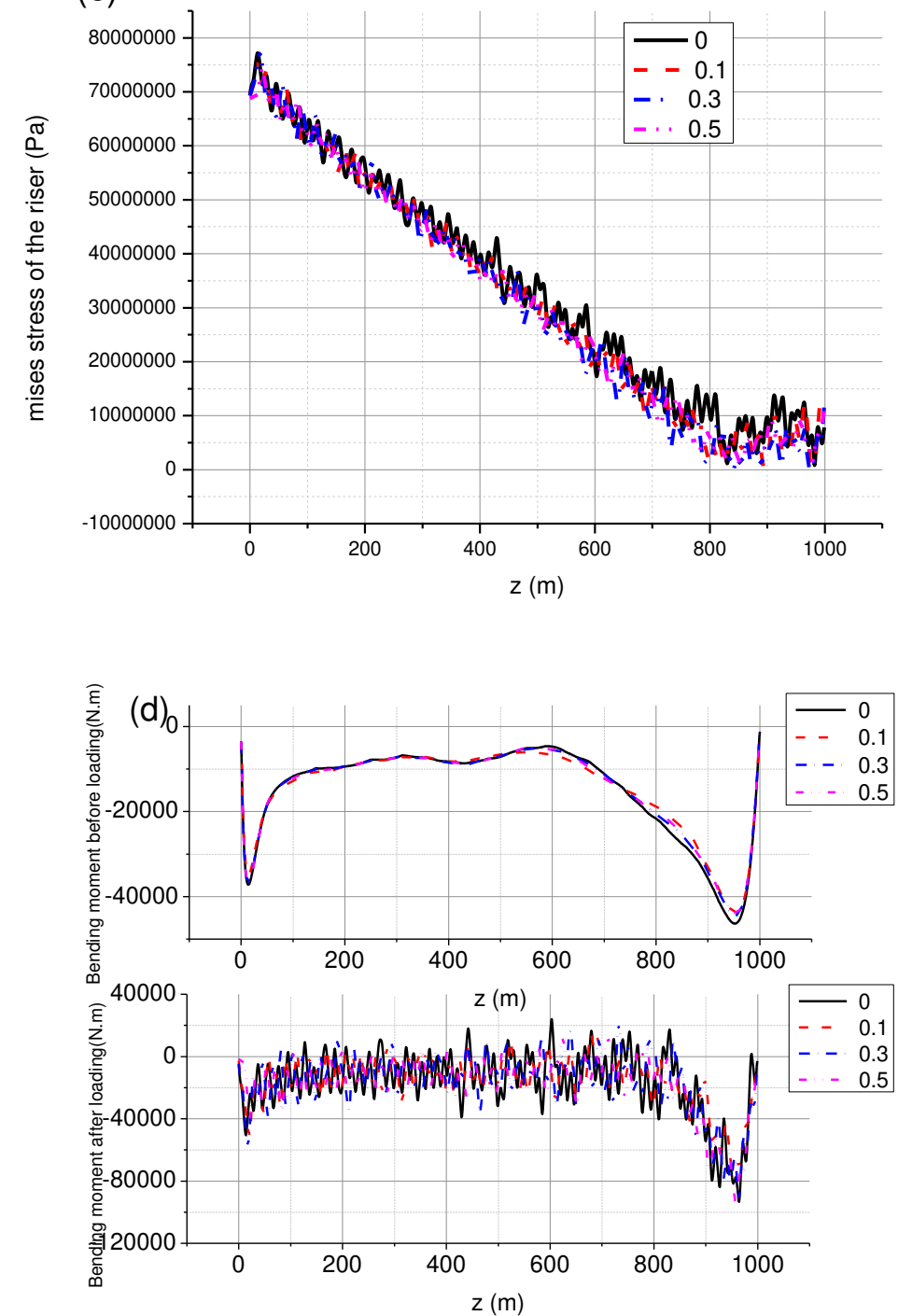
Fig. 8 Effect of the friction coefficient: (a) output force of the CT; (b) displacement of the riser; (c) Mises stress of the riser; (d) bending moment of the riser.

Fig. 8(a) shows that the larger the friction coefficient is, the smaller the end output force is. The difference of the output force in the friction coefficient of 0 and 0.5 is $78.44 \mathrm{KN}$.

Fig. $8(\mathrm{~b}) \sim(\mathrm{d})$ show that the friction coefficient has no influence on the displacement, stress and bending moment of the riser. The reason is that the lateral displacement of the riser is mainly caused by the external ocean load.

The growth of the friction coefficient reduces the transmission efficiency of the axial force, and the change of the friction coefficient has little effect on the riser.

\subsection{Effect of the environmental parameters}

The marine environment is unpredictable, and the load forms are also diverse. The impact of the environmental parameters including ocean depth, current speed, wave period, and wave height is analyzed in this section.

\section{(1) Water depth}

With the rise of the water depth, the dynamic response of the system becomes more complex. Three ocean depths of $800 \mathrm{~m}, 1000 \mathrm{~m}$ and $1200 \mathrm{~m}$ are chosen for calculation. The calculation results are shown in Fig. 9.
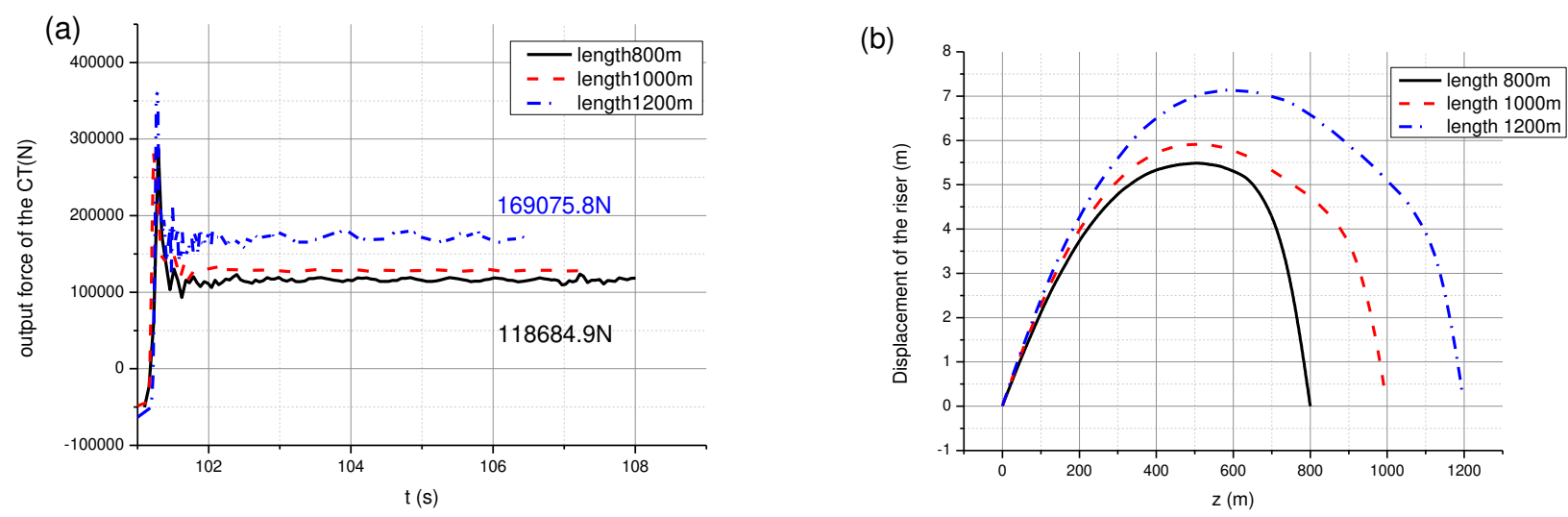

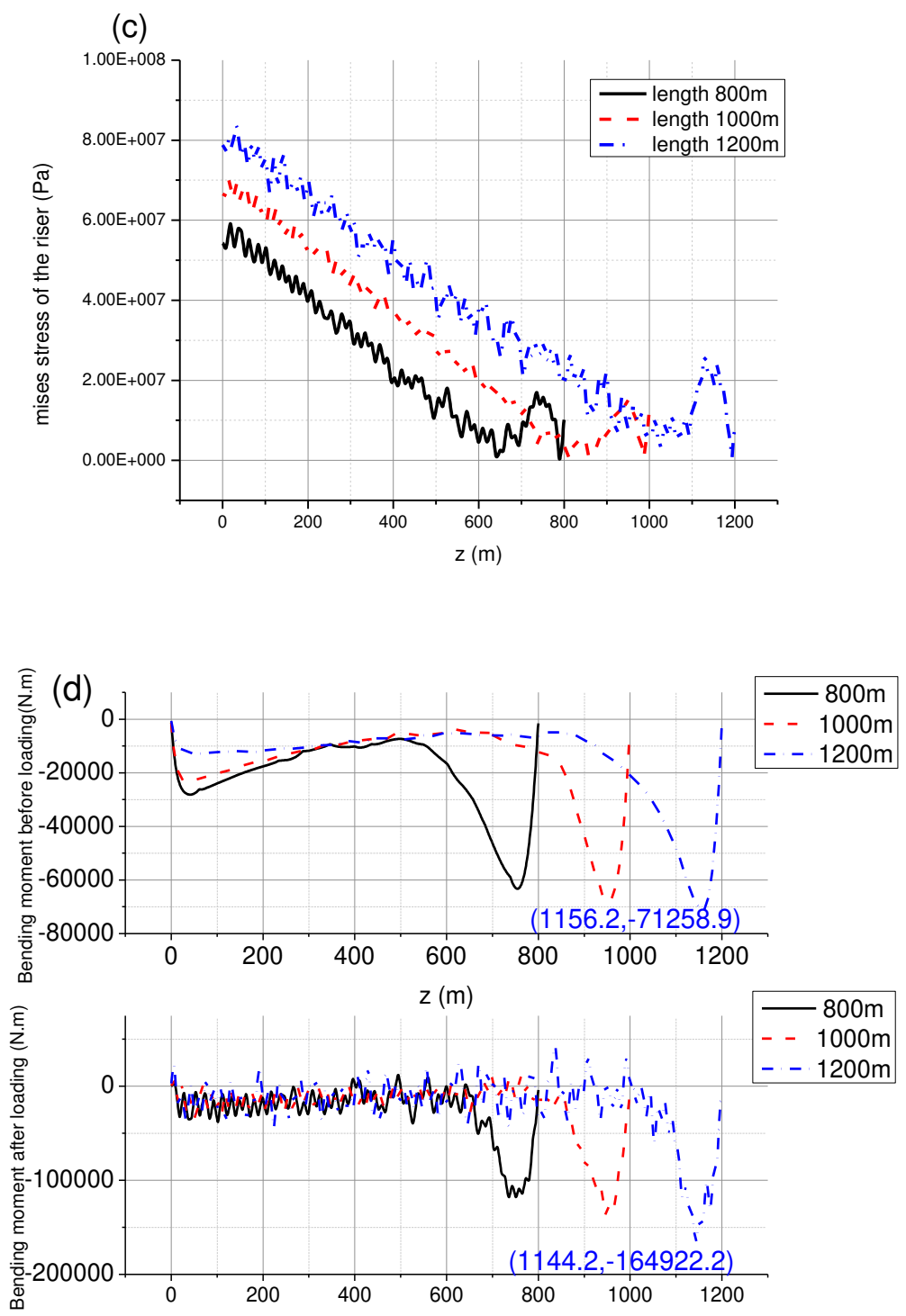

Fig.9 Effect of the water depth: (a) output force of the CT; (b) displacement of the riser; (c) Mises stress of the riser; (d) bending moment of the riser.

With the depth of the ocean increases, the output force of the CT is larger as shown in Fig. 9 (a). The average output force of depth $800 \mathrm{~m}$ is $118.68 \mathrm{KN}$, and that of depth $1200 \mathrm{~m}$ is $169.08 \mathrm{KN}$.

Fig. 9(b) shows that the lateral deformation of the CT-in-riser systems will be larger with the increase of the sea depth. The reason is that the CT-in-riser system is less stiffness with the increase of the water depth.

In Fig. 9(c), the Mises stress of the riser increases with the sea depth. The reason is that the riser in $1200 \mathrm{~m}$ of depth has increased top tension, which is a function of total riser submerged weight, 
than the other two riser configurations under the same conditions.

Fig. 9(d) shows that the water depth has some influence on the bending moment. The maximum bending moment occurs above the subsea wellhead. It can be seen that the bending moment of the riser has a significant increase after adding the external ocean loads. The increase of the maximum bending moment with a depth of $1200 \mathrm{~m}$ is $93.7 \mathrm{KN} \cdot \mathrm{m}$ when the injection force is applied.

In summary, the lateral displacement, stress and bending moment of the riser will increase with the growth of the water depth.

\section{(2) Current speed}

In order to discuss the influence of the current speed on the CT-in-riser systems, three ocean current speeds of $0.5 \mathrm{~m} / \mathrm{s}, 1 \mathrm{~m} / \mathrm{s}$ and $1.5 \mathrm{~m} / \mathrm{s}$ are selected for calculation. The calculation results are shown in Fig. 10.
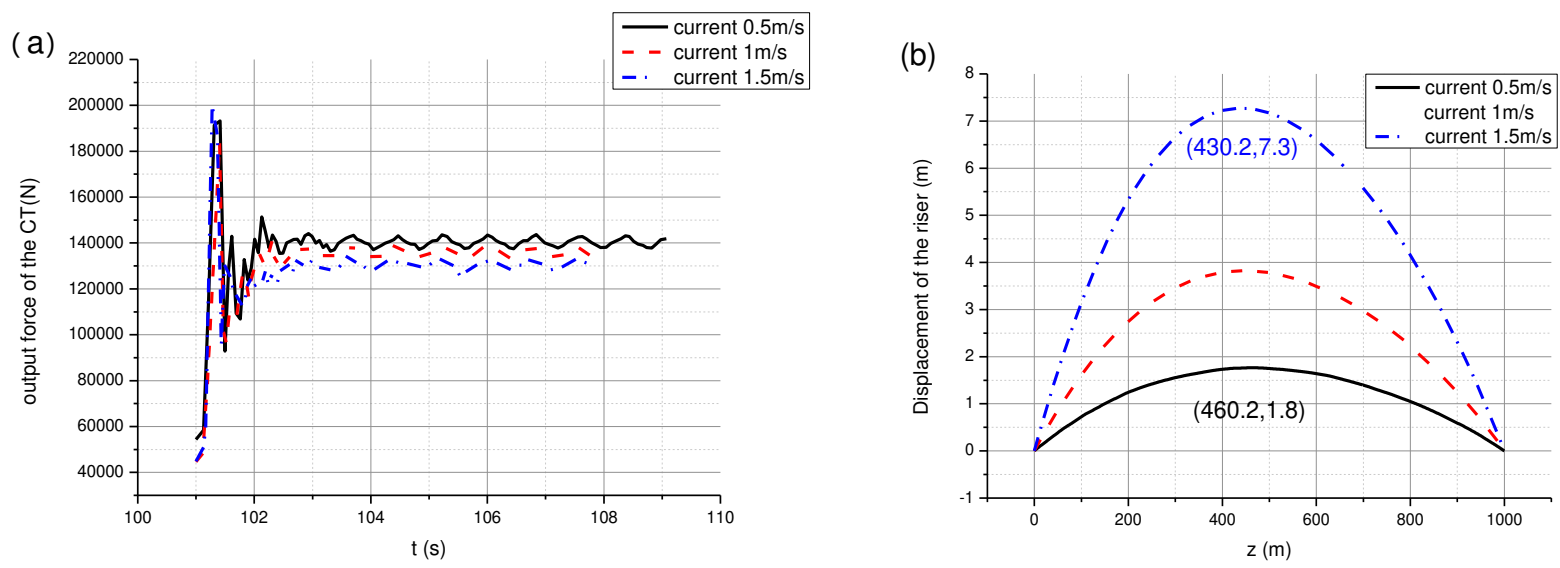

(c)

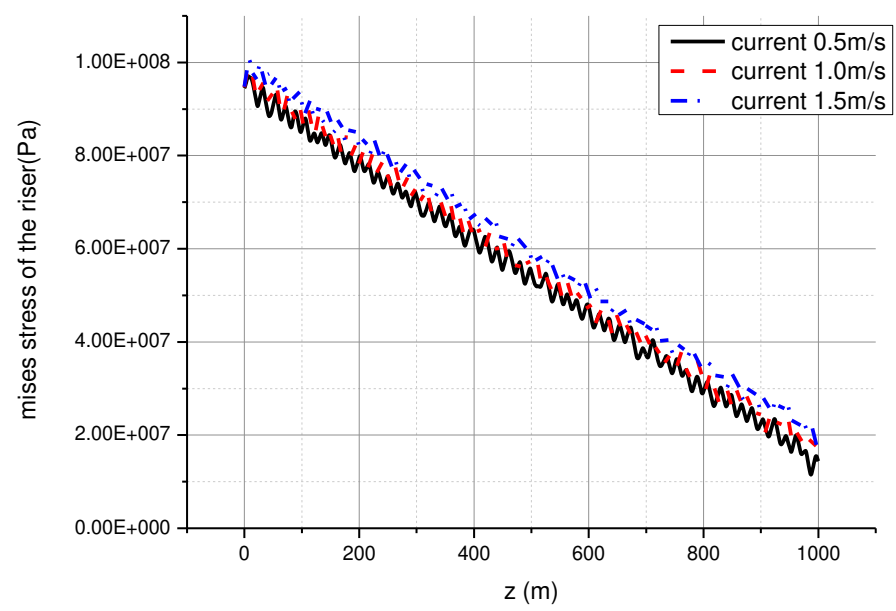




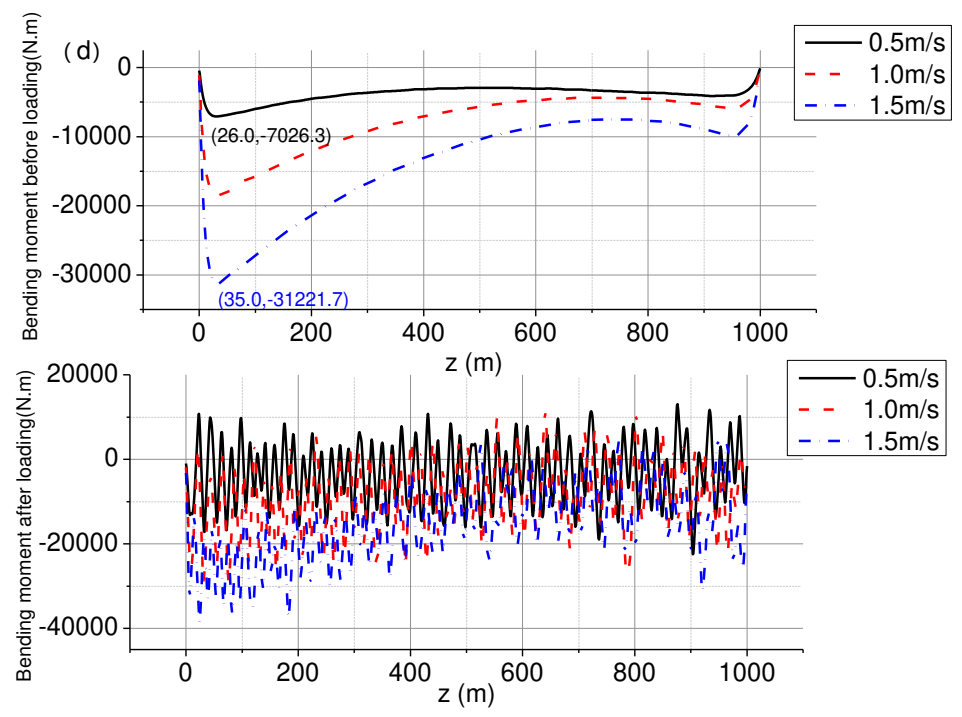

Fig.10 Effect of the current: (a) output force of the CT; (b) displacement of the riser; (c) Mises stress of the riser; (d) bending moment of the riser.

Fig. 10(a) shows that the average axial force of the CT will decrease with the increased current speed. It leads by an increase of contact friction. Fig. 10(b) indicates that the greater the current speed is, the greater the lateral displacement of the system is. The maximum displacement difference between $1.5 \mathrm{~m} / \mathrm{s}$ and $0.5 \mathrm{~m} / \mathrm{s}$ reaches $5.5 \mathrm{~m}$.

Fig. 10(c) shows that the greater the current speed is, the greater the Mises stress is. With the current speed increases, the overall bending moment of the riser increase as shown in Fig. 10(d). The maximum difference of the bending moment reaches $24.2 \mathrm{KN} \cdot \mathrm{m}$ without injection force. The bending moment of the riser has a fluctuation when the injection force is loading.

In summary, the current speed will have a negative effect on the safety of the CT-in-riser systems.

\section{(3) Wave period}

The natural frequency of the CT-in-riser system can be calculated through the simulation model. The first $10^{\text {th }}$ order frequency of the system is shown in Table 3.

Table 3 First $10^{\text {th }}$ order frequency of the CT-in-riser system.

\begin{tabular}{|c|c|c|c|c|c|c|c|c|c|c|}
\hline Order & 1 & 2 & 3 & 4 & 5 & 6 & 7 & 8 & 9 & 10 \\
\hline $\begin{array}{l}\text { Frequency of CT-in-riser } \\
\qquad(\mathrm{Hz})\end{array}$ & 0.1396 & 0.2109 & 0.2826 & 0.4243 & 0.4280 & 0.5771 & 0.6374 & 0.7308 & 0.8504 & 0.8898 \\
\hline
\end{tabular}


Table 3 shows that the frequency increases along the growth of the order. To prevent the resonance of the system, four wave periods of $10 \mathrm{~s}, 20 \mathrm{~s}, 30 \mathrm{~s}$ and $40 \mathrm{~s}$ are selected, and the corresponding frequency is $0.1 \mathrm{~Hz}, 0.05 \mathrm{~Hz}, 0.03 \mathrm{~Hz}$, and $0.025 \mathrm{~Hz}$, respectively. The minimum difference is more than $30 \%$ when the wave frequency is $0.1 \mathrm{~Hz}$, and then it has no resonance in this simulation. The calculation results are shown in Fig. 11.
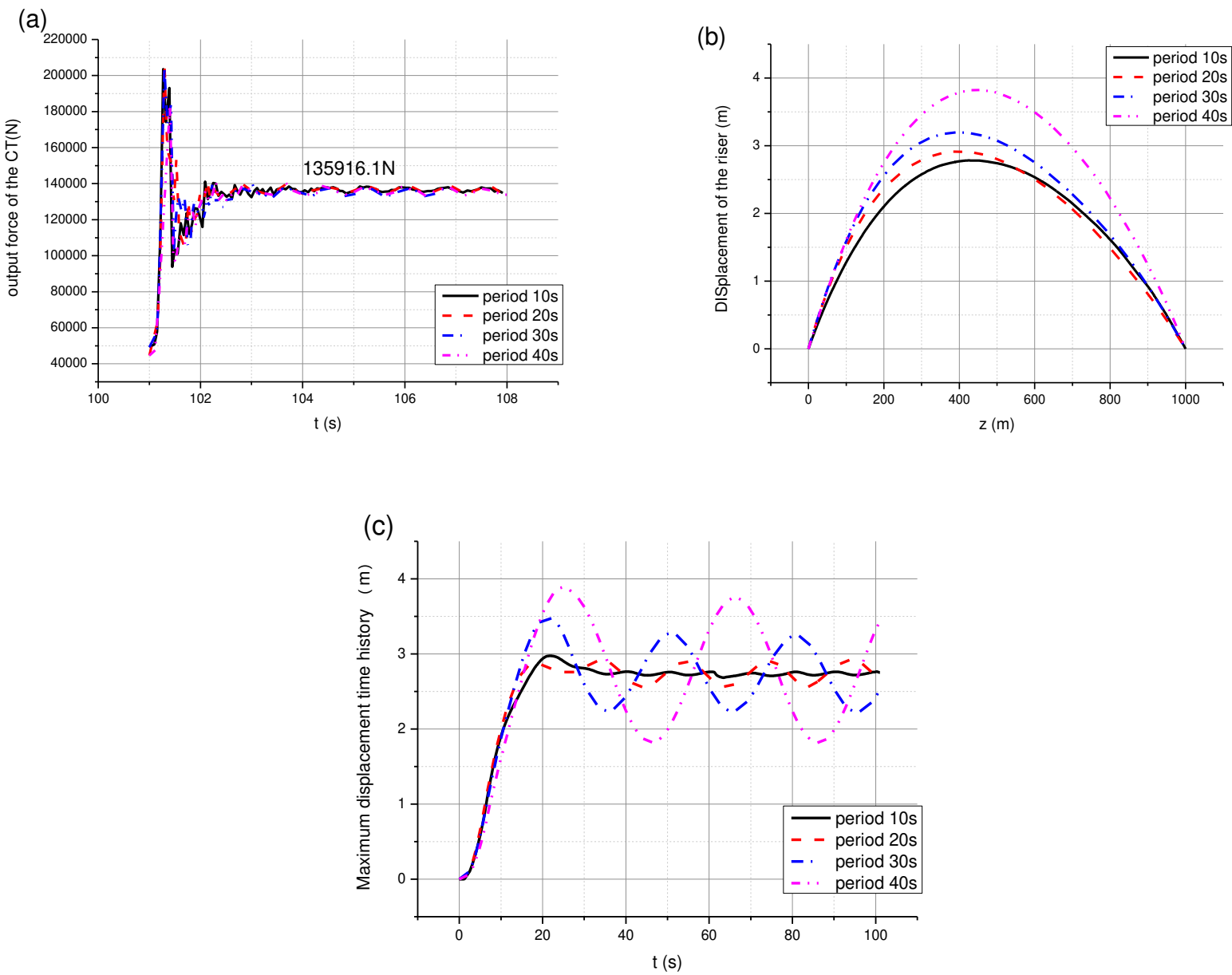


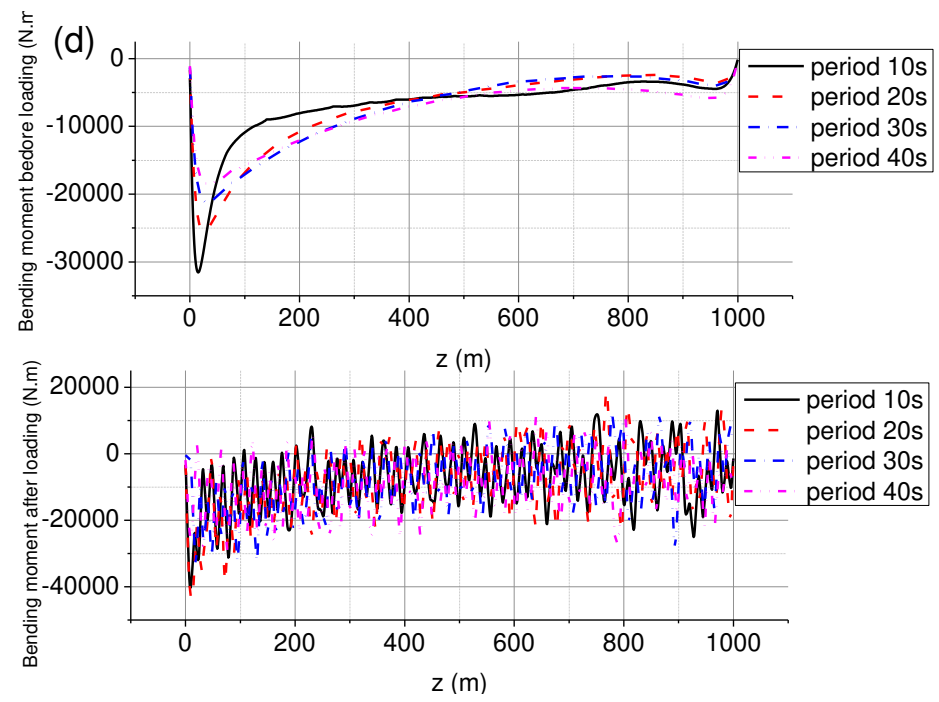

Fig.11 Effect of the wave period: (a) output force of the CT; (b) displacement of the riser; (c) Mises stress of the riser; (d) bending moment of the riser.

Fig. 11(a) shows that the wave period has little effect on the output force. Fig. 11(b) indicates that the higher the period of the wave is, the greater the maximum lateral displacement of the CT-in-riser systems is.

The time history of the maximum displacement is extract as shown in Fig. 11(c). It can be seen that the average lateral displacement is about $2.7 \mathrm{~m}$. Under a low-frequency cyclic load, the systems have a sufficient time response, and then the oscillation of the displacement period is obvious.

Fig. 11(d) shows the lower the wave period, the greater the maximum bending moment of the riser, regardless of whether loading the injection force of the CT.

The change of wave period has little effect on the axial force transmission. However, the growth of wave period increases the lateral displacement and decreases the bending moment.

\section{(4) Wave height}

The wave heights of $4 \mathrm{~m}, 6 \mathrm{~m}$ and $8 \mathrm{~m}$ are selected and the calculation results are shown in Fig. 12. 

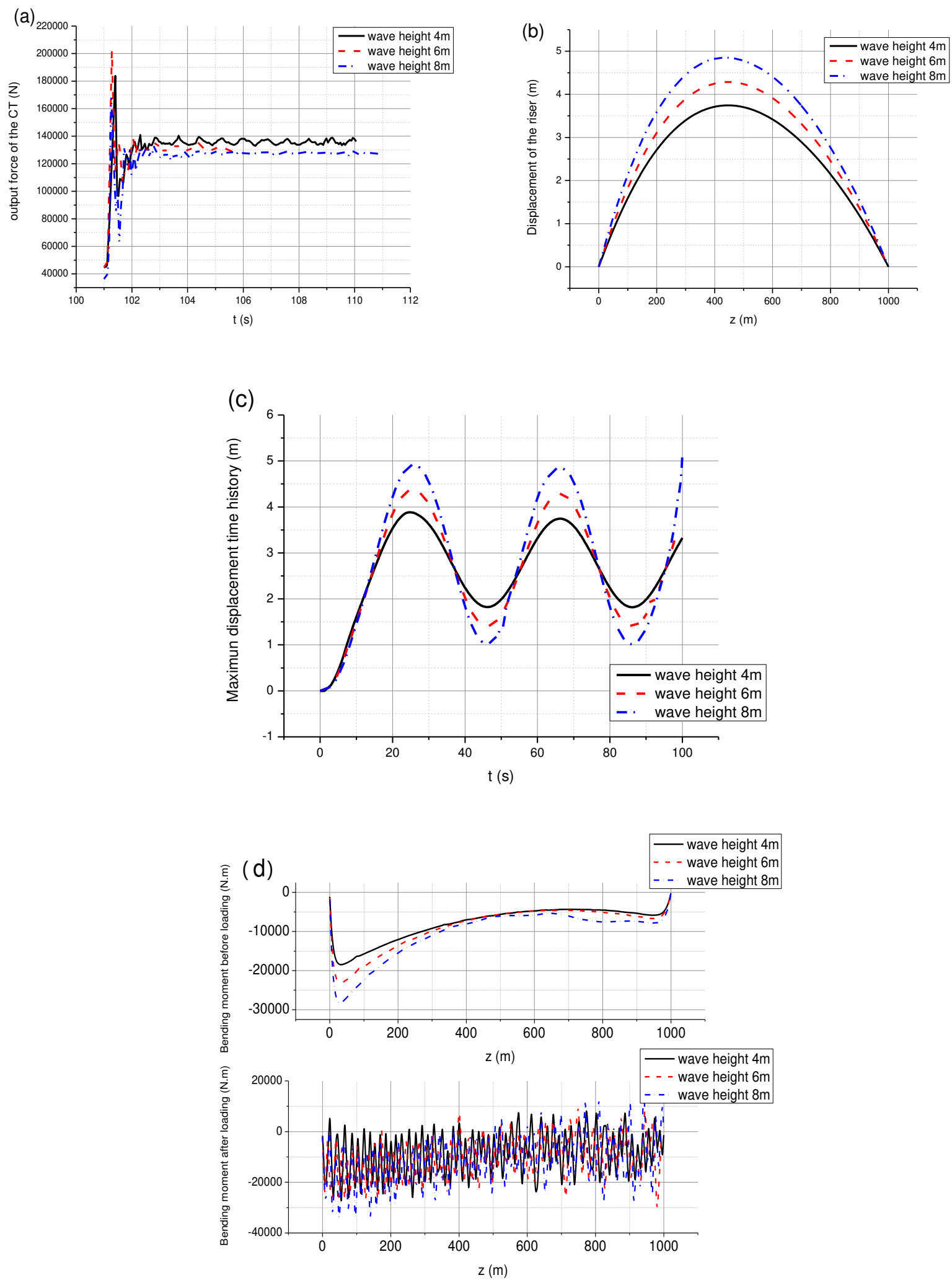

Fig.12 Effect of the wave height: (a) output force of the CT; (b) displacement of the riser; (c) Mises stress of the riser; (d) bending moment of the riser. 
Fig. 12(a) shows the wave height has a little effect on the axial force transmission of the CT. Fig. 12(b) indicates that with the increased wave height, the lateral displacement will rise up.

The time history of the maximum displacement is extracted as shown in Fig. 12(c). It can be seen that the larger the wave height is, the larger the lateral displacement is.

Fig.12 (d) shows the distribution of the bending moment of the riser. Regardless of whether loading the CT injection force, the bigger the wave height is, the larger the bending moment of the riser is.

In summary, the wave height has a little effect on the axial force transmission of the CT, but the lateral displacement and the bending moment will rise up along the increase of the wave height.

\section{Conclusions}

In the present work, the coupled dynamic model of the CT-in-riser system was proposed, and the influencing factors on the system considering the operational and environmental parameters were investigated.

A coupled model of CT-in-riser systems was described. In order to solve it, a 3D finite element model by ABAQUS/AQUA module was built. Though changing the load and boundary conditions, the effects of the operational and environmental parameters were discussed. About operation parameters, the top injection force in a certain range and the friction coefficient have little effect on the lateral displacement, stress and bending moment of the riser; the growth of riser top tension and annular clearance reduce the bending moment of the riser; the platform offset increases the displacement, stress, and bending moment of the riser; top tension improve the axial force transmission, and the increase of the annular clearance and friction coefficient decrease the transmission efficiency of the axial force. The results show that the top tension should be properly controlled, platform offset and friction coefficients (Egberts et al., 2018) [24] should be reduced, and the annular clearance should be appropriately reduced. About environmental parameters, with the growth of water depth, current speed, wave height, the lateral displacement and bending moment will rise up; the wave period and wave height have little effect on the axial force, and the increase of the current speed will decrease the axial force transmission. The results indicate that it is necessary to select a condition with low current speed and wave height for operation, while the wave period and 
wave height have little effect to the CT axial force. In summary, in order to ensure safe operation, a small platform offset, annular clearance, current speed, wave height, and an appropriate top tension should be selected.

\section{Acknowledgment}

This work was supported by National Natural Science Foundation of China (No. 51309237, No. 51709006) and Science Foundation of China University of Petroleum, Beijing (No. ZX20150082, C201602).

\section{Reference}

[1] Freitas AM. Formation and Removal of a Hydrate Plug Formed in the Annulus Between Coiled Tubing and Drill String. 2005.

[2] Lasseigne B, Lindsey BJ, Larke J. Performing Riserless Subsea Operations Utilizing Coiled Tubing in Open Water. SPE/ICoTA Coiled Tubing \& Well Intervention Conference \& Exhibition; 2015/3/24/; The Woodlands, Texas, USA. SPE: Society of Petroleum Engineers; 2015. p. 9.

[3] Arrieta VV. Case History: Lessons Learned From Retrieval of Coiled Tubing Stuck by Massive Hydrate Plug When Well Testing in an Ultradeepwater Gas Well in Mexico. 2011.

[4] Pinto JCA. Pioneer Coiled Tubing Intervention Onboard Floating Production Storage and Offloading Vessel (FPSO) Offshore Brazil. 2010.

[5] Mark J. Kaiser. A Review of Deepwater Pipeline Construction in the U. S. Gulf of Mexico-Contracts, Cost, and Installation Methods[J]. Journal of Marine Science and Application , 2016, 15(3): 288-306.

[6] Aker Solutions Company. http://subsea-equipment.com/2016/11/09/aker-solutionsmodularized- workover -system/

[7] Wang W, Zhang S, Chen Y, Wang D, Liu S. 2012. Application of CT in Offshore Operation [J]. China Petroleum Machinery, 40 (11):53-57.

[8] Gao DL, Huang WJ. A review of down-hole tubular string buckling in well engineering[J]. Petroleum Science. 2015;12(3):443-57.

[9] Hong KS, Shah UH. Vortex-induced vibrations and control of marine risers: A review. Ocean Engineering. 2018;152:300-15. 
[10] Alrsai M, Karampour H, Albermani F. Numerical study and parametric analysis of the propagation buckling behaviour of subsea pipe-in-pipe systems. Thin-Walled Structures. 2018;125:119-28.

[11] Falser S, Bridge C, Palmer A C. 2010. Interaction between a compliant guide and a the CT during sub-sea well intervention in deep water [J]. Applied Ocean Research, 32(4):454-459.

[12] Guan F, Duan M, Ma W, Zhou Z, Yi X. An experimental study of mechanical behavior of coiled tubing in pipelines. Applied Ocean Research. 2014;44:13-9.

[13] Guan F. The helical buckling analysis of coiled tubing in offshore pipelines. Ships and Offshore Structures. 2019;14(2): 193-203.

[14] Chen Y, Zhang S, Wang W, Xiong M. 2016. Experimental study on axial load transfer behavior of a the CT stuck in a marine riser [J]. Proceedings of the Institution of Mechanical Engineers Part M-Journal of Engineering for the Maritime Environment. 230(2):241-9.

[15] Chen Y, Zhang S, Wang W, Xiong M, Zhang H. 2017. Experimental study on axial load transfer behavior of a the CT stuck in a steel catenary riser: At the stage of the the CT un-helical buckled [J], Part M: Journal of Engineering for the Maritime Environment. 231(2)355-363.

[16] Chen Y, Wang X, Wang W, et al. 2018. Chen, Yingchun; Wang, Xinhua; Wang, Wenming Study on the mechanics of a the CT within a marine 'pipe-in-pipe' system with a low diameter ratio[J]. Ships \& Offshore Structures, 13(4): 385-391.

[17] Wang WM, Li H, Chen Y, Peng H. Experimental and theoretical study on the effect of inclined angle in the SCR pipe-in-pipe system. Ocean Engineering. 2018;154:389-95.

[18] Morooka CK, Bueno RCS. 1997. Drill column-riser-wellbore contact forces in a floating drilling rig in waves[J]. Transactions on the Built Environment.

[19] Wang P, Yan T, Liu S, Yu S, Zhang Q. 2014, A Coupled Mechanical Model of Deep Water Riser and the Drill string [J]. Journal of Oil and Gas Technology, (06):83-86+6.

[20] Wang Y, Gao D, Fang J. Coupled dynamic analysis of deepwater drilling riser under combined forcing and parametric excitation. Journal of Natural Gas Science and Engineering. 2015;27:1739-47.

[21] Mao L, Liu Q, Zhou S, Wang G, Fu Q. 2016. Deep water drilling riser mechanical behavior analysis considering actual riser string configuration. Journal of Natural Gas Science and Engineering.33:240-54. 
[22] Liao M, Zhou Y, Su Y, Lian Z, Jiang H. Dynamic analysis and multi-objective optimization of an offshore drilling tube system with pipe-in-pipe structure. Applied Ocean Research. 2018;75:85-99.

[23] Faes K, Kwee I, De Waele W. Electromagnetic Pulse Welding of Tubular Products: Influence of Process Parameters and Workpiece Geometry on the Joint Characteristics and Investigation of Suitable Support Systems for the Target Tube. Metals. 2019;9(5).

[24] Egberts P, Simin N, Wong C, Czibor J, Ewanchuk C, Park S. A Novel Tribometer Designed to Evaluate Geological Sliding Contacts Lubricated by Drilling Muds. Journal of Testing and Evaluation. 2019;47(6). 